\title{
RIOLITAS EL UVO
}

\Cordillera Oriental Departamento de Santander

Gilberto Zapata, María Isabel Arango, Ana María Correa Martínez y Gabriel Rodríguez

Catálogo de las unidades litoestratigráficas de Colombia / Jurásico

Citación: Zapata, G., Arango, M. I., Correa Martínez, A. M. y Rodríguez, G. (2020). Riolitas El Uvo. En Catálogos de las unidades litoestratigráficas de Colombia: Macizo de Santander. Vol. 1. Servicio Geológico Colombiano. https://doi.org/10.32685/9789585279445.7 
En el desarrollo del proyecto Magmatismo Jurásico en el Macizo de Santander, llevado a cabo por el grupo de Estudios Geológicos Especiales de la regional Medellín del Servicio Geológico Colombiano, en el Batolito de Mogotes se encontró un cuerpo de riolitas que no estaba cartografiado ni referenciado en la bibliografía geológica. La mayor parte del cuerpo aflora en el extremo oriental-suroriental de la Plancha 136, Málaga, y en una menor proporción en el extremo nororiental la Plancha 152, Soata, planchas del Ingeominas a escala 1:100.000. Este cuerpo de rocas volcánicas compone una unidad geológica que se denominó Riolitas EI Uvo.

En este catálogo se presentan las características del cuerpo subvolcánico Riolitas El Uvo, determinadas por el Servicio Geológico Colombiano (SGC), donde se incluyen su presencia en campo, datos petrográficos macro y microscópicos, geoquímicos y una datación geocronológica $\mathrm{U} / \mathrm{Pb}$ en circón por el método LA-ICP-MS, las posibles correlaciones del cuerpo con otros semejantes de la región y un análisis general del potencial mineral de la unidad. Con el presente trabajo se pretende contribuir al conocimiento de la geología del Macizo de Santander y de los eventos magmáticos del Jurásico en Colombia.

\section{Proponente del nombre}

El nombre Riolitas El Uvo es propuesto por los autores del presente Catálogo, siguiendo las recomendaciones de la International Subcommission on Stratigraphic Classification of IUGS $(1987,1994)$. La denominación tiene en cuenta la litología dominante y el nombre geográfico de donde se describió originalmente la unidad.

\section{Origen del nombre y distribución geográfica}

El nombre de este cuerpo proviene de la composición modal dominante, que son rocas hipoabisales de composición riolítica y de su localización geográfica.

La unidad Riolitas El Uvo aflora en dos planchas geológicas del Ingeominas: 136, Málaga (Vargas et al., 1984) y 152, Soatá (Vargas et al., 1987), a escala 1:100.000, sobre la vía vereda Santa Fe-El Uvo, en el municipio de San Joaquín, departamento de Santander (figura 1) y se presenta como un cuerpo alargado en sentido norte-sur, con un área aproximada de 16 km².

\section{Reseña histórica}

Las Riolitas El Uvo no aparecen en la cartografía regional de las planchas 136, Málaga (Vargas et al., 1984) y 152, Soatá (Vargas et al., 1987), a escala 1:100.000, ni son mencionadas en la memoria de esas planchas (Vargas et al., 1981), donde el área en la que aflora la unidad de riolitas está cartografiada y descrita como Cuarzomonzonita biotítica blanca a rosada (JRcm) o Batolito de Mo- gotes. En el presente trabajo se delimita su contorno con base en la cartografía de campo y fotointerpretación, se describe su litología y con petrografía se define la composición modal predominante.

\section{Descripción geológica}

Las Riolitas El Uvo afloran al oeste de la falla de Bucaramanga, en el sector suroccidental del Macizo de Santander, y están enmarcadas por el Monzogranito de Mogotes al cual intruyen.

\subsection{Marco geológico}

El Macizo de Santander, localizado en la cordillera Oriental de Colombia, está enmarcado por un bloque de forma triangular delimitado al occidente por las fallas de Santa Marta-Bucaramanga, al norte por la falla de Oca, y al oriente por la falla de Boconó.

El basamento del Macizo de Santander incluye rocas metamórficas del Neis de Bucaramanga (Ward et al., 1973) conformado por paraneises migmatíticos de alto grado con edad proterozoica (García y Ríos, 1999; Ordóñez et al., 2006) con un pico de metamorfismo en $1057 \pm 28 \mathrm{Ma}$ U/Pb-Shrimp en circones, edad relacionada con la orogenia Grenvilliana. Estudios más recientes (Van der Lelij, 2013; Van der Lelij et al., 2016; Zuluaga et al., 2017; Rodríguez et al., 2017) obtuvieron edades de metamorfismo de $477 \mathrm{Ma}$, correspondientes a la orogenia Caparonensis o Famatiniana. 

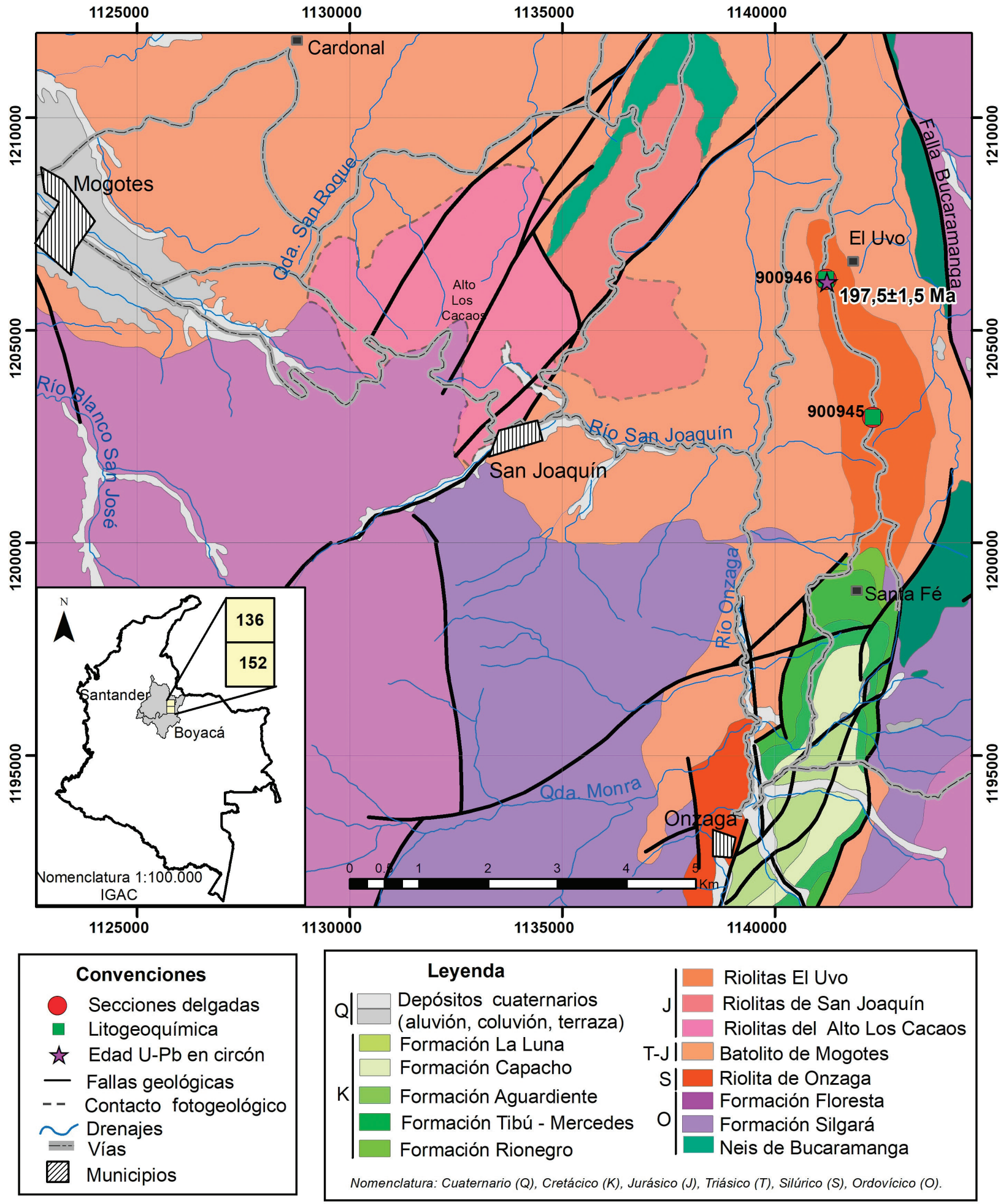

Figura 1. Mapa geológico generalizado de parte de las planchas 136, Málaga, y 152, Soatá, a escala 1:100.000, donde se muestra ubicación de las Riolitas El Uvo, localización de las muestras con sección delgada, geoquímica y datación.

Fuente: modificado a partir de Vargas et al. (1984) y Vargas et al. (1987). Datos de este trabajo 
Al neis lo suprayace la Formación Silgará, compuesta por ortoanfibolitas, esquistos, filitas, metalodolitas, metaareniscas y mármoles con edades de metamorfismo del Ordovícico inferior-medio (Forero, 1990; Ríos et al., 2003; Ordóñez-Cardona et al., 2006; Clavijo et al., 2008; Mantilla et al., 2013). Algunas edades U/Pb en circón muestran magmatismo posterior al metamorfismo, representado por metavulcanitas y plutones que intruyen el basamento metamórfico, con edades $\mathrm{U} / \mathrm{Pb}$ en circón del Silúrico, Devónico inferior, Carbonífero y límite Triásico-Jurásico.

En el límite de los periodos Triásico y Jurásico, dentro del basamento metamórfico, en la margen occidental del Macizo de Santander, se desarrolló magmatismo de arco, con emplazamiento de cuerpos graníticos y riolíticos subvolcánicos (Goldsmith et al., 1971; Ward et al., 1973; Van der Lelij, 2013).

Las unidades sedimentarias cretácicas reposan inconformemente sobre el basamento metamórfico y los plutones. Durante el Mioceno se presentó un nuevo magmatismo, que emplazó pequeños cuerpos de pórfidos con mineralizaciones de oro (Leal Mejía, 201 1; Mantilla et al., 2013).

\subsection{Características macroscópicas}

Las Riolitas El Uvo son rocas faneríticas inequigranulares de grano medio a fino, porfídicas, leucocráticas, con matriz afanítica felsítica, con microfenocristales subredondeados y bipiramidales de cuarzo, cuyo tamaño varía de 0,2 a $10 \mathrm{~mm}$, cristales subhedrales de feldespato potásico de color rosado con tamaños de 0,1 a 0,8 mm, cristales prismáticos de plagioclasa y biotita en láminas de color negro, con bordes oxidados (figura 2).

\subsection{Características microscópicas}

De las Riolitas El Uvo se analizaron dos secciones delgadas que corresponden a rocas porfídicas holocristalinas, compuestas por cuarzo (38,9\% a 39,6\%), feldespato potásico (40\% a 46,2\%), plagioclasa ( $11,4 \%$ a $18,4 \%)$, biotita (1\%) (tabla 1). Como minerales accesorios se encuentran opacos, apatito, prehnita y allanita con $\leq 1 \%$, y de alteración epidota. Los porcentajes se obtuvieron con el conteo de puntos en el análisis petrográfico, y en la clasificación modal se utilizó el diagrama QAP para rocas volcánicas de Streckeisen (1978). Ambas muestras se clasifican como riolitas (figura 3).
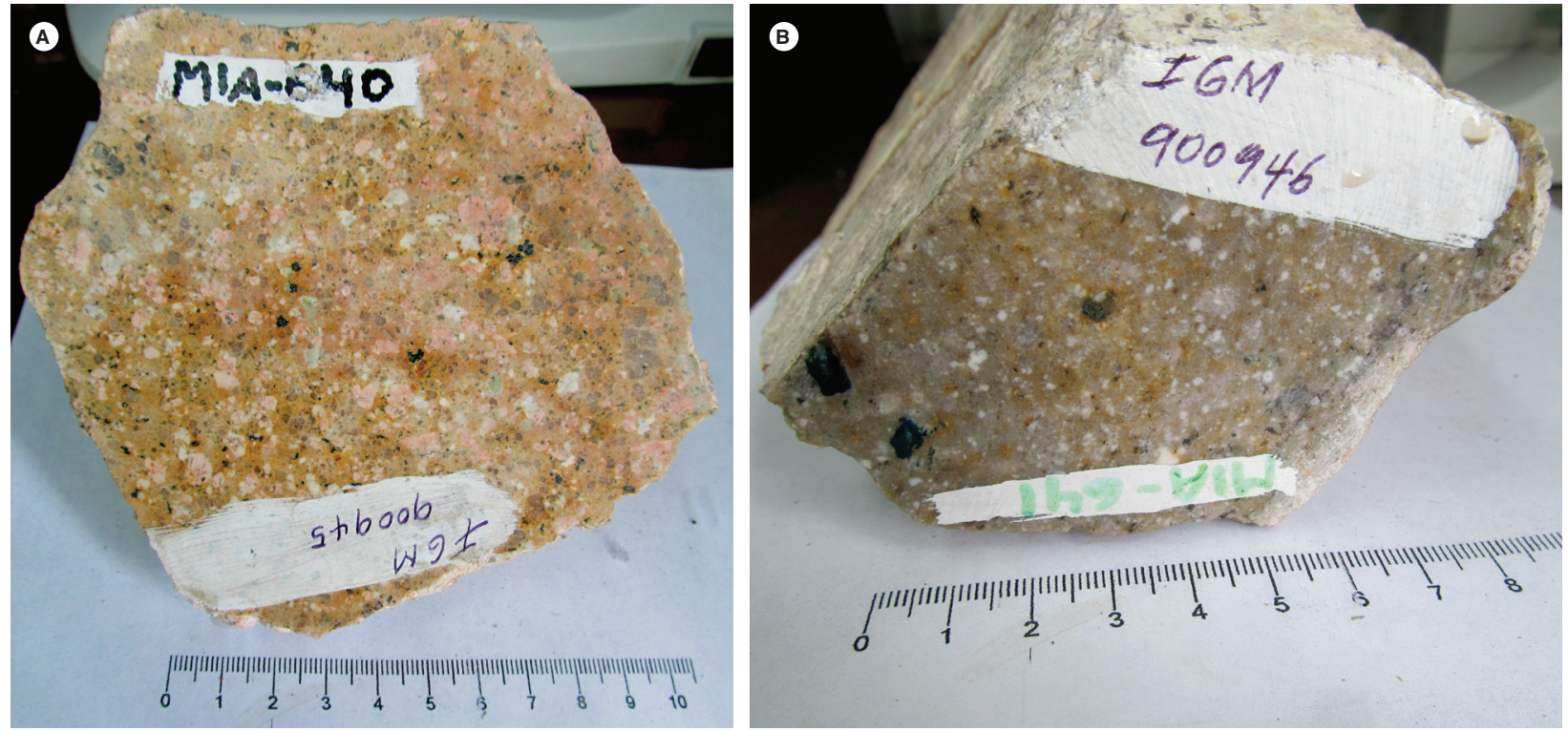

Figura 2. Aspecto macroscópico de las rocas de las Riolitas El Uvo. Textura porfídica 
La textura general es microporfídica (figura 4). También se presentan texturas glomeroporfídica, poiquilítica, pertitas, mirmequitas, micrográfica y de reabsorción. La matriz es microcristalina felsítica en agregados de cuarzo y feldespato (figura 4). En una de las muestras hay agregados microgranofídicos, y en la otra, biotita y opacos, que también hacen parte de los agregados mi- crocristalinos. La relación matriz (52\% a 56,2\%)/fenocristales $(43,8 \%$ a $48 \%)$ es de aproximadamente 1:1. La muestra IGM 900945 tiene $1 \%$ de amígdalas.

Las principales alteraciones son argilización del feldespato potásico, sericitización de la plagioclasa y cloritización de la biotita. El grado de alteración de las muestras es moderado.

Tabla 1. Composición modal de las Riolitas El Uvo

\begin{tabular}{ccccccccccccc}
\hline IGM & Este & Norte & Qtz & PI & Kfs & Bt & Op & Ap & Prh & Matriz & Fenocristales & Clasificación petrográfica \\
\hline 900945 & 1142307 & 1202953 & 38,9 & 11,4 & 46,2 & 1 & 0,5 & 1 & 1 & 56,2 & 43,8 & Riolita porfídica \\
\hline 900946 & 1141207 & 1206200 & 39,6 & 18,4 & 40 & 1 & 1 & $\mathrm{Tr}$ & 48 & 52 & Riolita porfídica \\
\hline
\end{tabular}

1 Traquita de fedespato alcalino

$1^{*}$ Cuarzo trquita de feld. alcalino

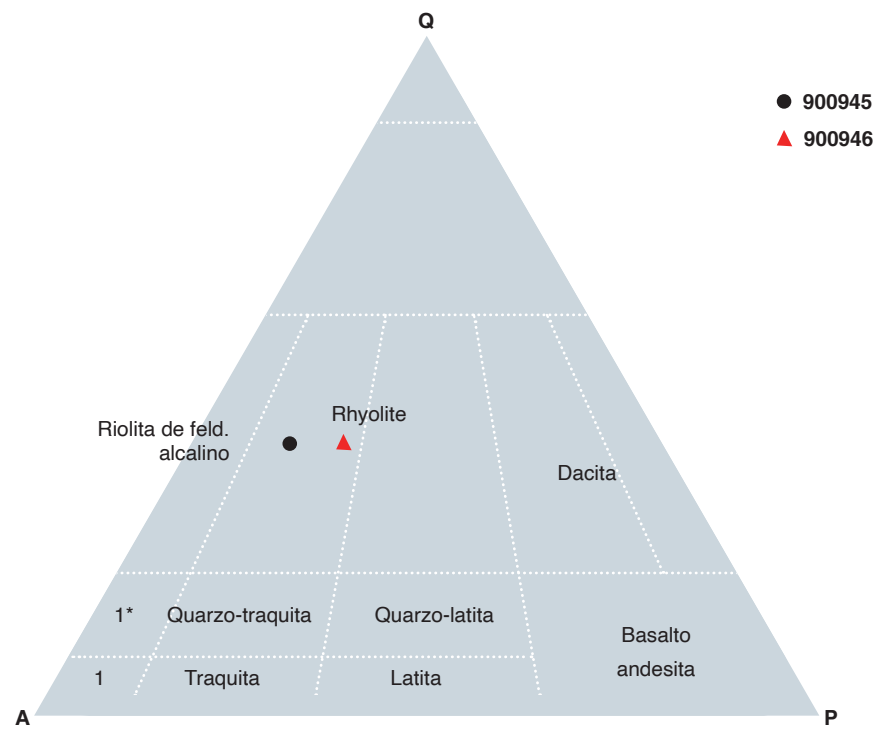

Figura 3. Clasificación modal de las rocas de las Riolitas El Uvo en el triángulo de Streckeisen (1978).

El feldespato potásico se encuentra en cristales individuales y en glomerocristales xenomórficos a subidiomórficos, alterados a caolín, de aspecto empolvado. El color de interferencia es gris del primer orden, con texturas de exsolución en forma de pertitas y textura micrográfica. Cristales de tamaños que oscilan entre 1,1 y $5 \mathrm{~mm}$. Los cristales de feldespato potásico muestran inclusiones poiquilíticas de plagioclasa (figura 4).

Los fenocristales y microcristales de cuarzo tienen tamaños de 0,3 a $7 \mathrm{~mm}$, exhiben formas subidiomórficas bipiramidales (figura 4C), algunos, con bordes corroídos por la matriz; son incoloros, con inclusiones fluidas alineadas y de rutilo en agujas finas.

La plagioclasa es andesina $\left(\mathrm{An}_{32-34}\right)$ y se presenta en cristales tabulares subidiomórficos alterados a sericita (figura 4 C, D), con maclas de albita, y sus tamaños varían de 0,9 a 1,2 $\mathrm{mm}$. Presenta texturas mirmequíticas en los bordes de los fenocristales por reacción con la matriz. 

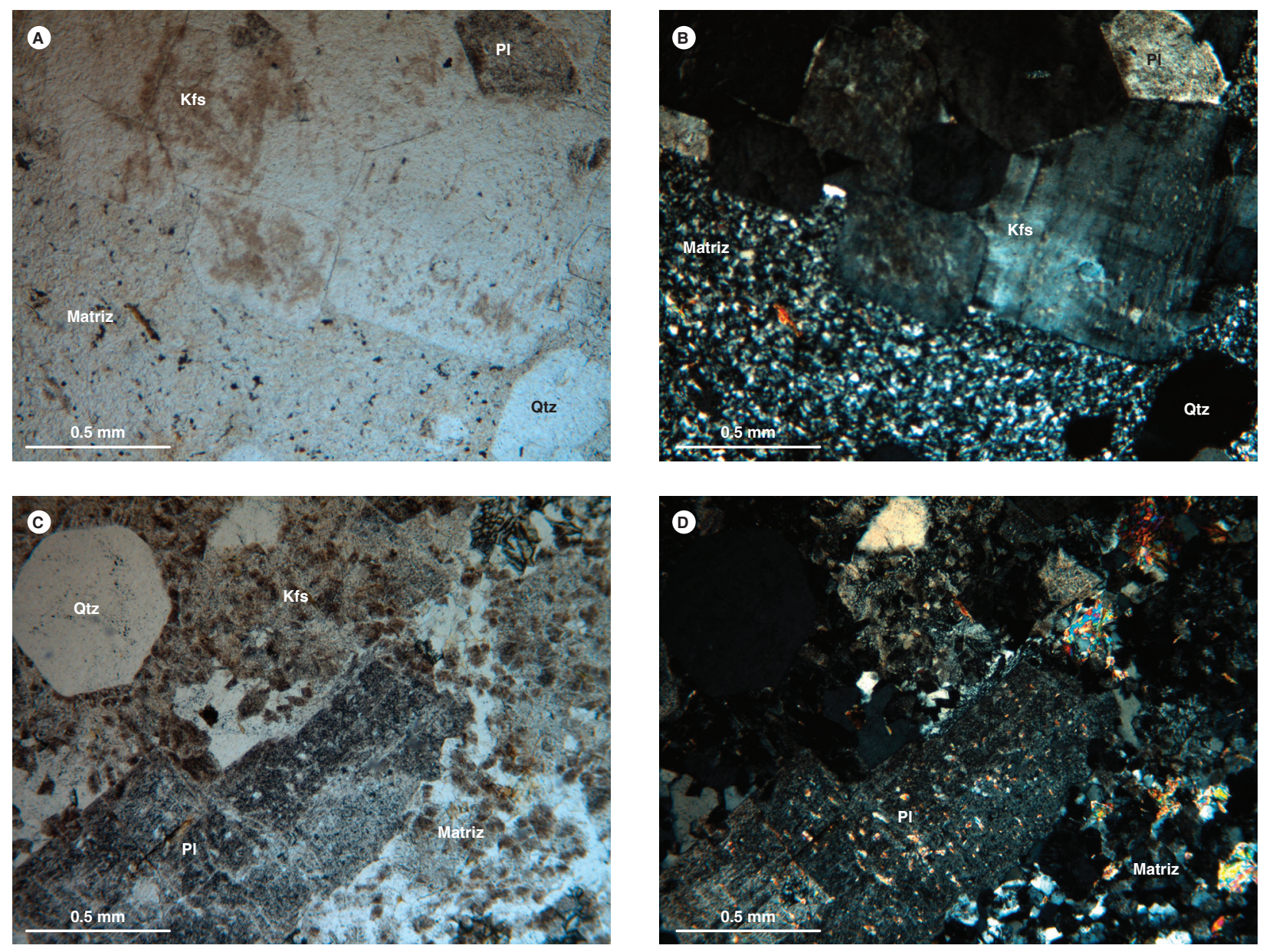

Figura 4. Características microscópicas de las riolitas. Objetivo 4X.

A) IGM 900946, nícoles paralelos. B) IGM 900946, nícoles cruzados. Matriz felsítica microgranular (Matriz), glomerocristales de feldespato potásico (Kfs) y cristales de plagioclasa (PI) y cuarzo (Qtz). C) IGM 900945, nícoles paralelos. D) Nícoles cruzados. Textura porfídica, matriz felsítica (Matriz), fenocristales de cuarzo $(\mathrm{Qtz})$, feldespato $(\mathrm{Kfs})$ y plagioclasa $(\mathrm{PI})$

La biotita se observa como láminas tabulares subidiomórficas de color castaño, pleocroicas. X: castaño claro, Y: castaño fuerte, con color de interferencia amarillo naranja del segundo orden. Los cristales tienen inclusiones de circón, allanita, opacos y titanita, y presentan alteración a clorita y epidota. Los tamaños de los cristales van de 0,6 a $1 \mathrm{~mm}$. La biotita también se encuentra en la matriz como láminas intersticiales finas, con tamaño 0,03 mm.

En las muestras se encuentran algunos cristales de allanita de forma alargada, de color pardo rojizo, levemente pleocroicos, con relieve alto. El color de interferencia está enmascarado por el color del mineral. Su tamaño es de 0,2 mm.

La titanita está en cristales incoloros xenomórficos de relieve alto, con colores de interferencia del tercer orden. Tamaño: 0,2 mm.
La prehnita se encuentra rellenando vesículas irregulares con diámetros $\leq 1 \mathrm{~mm}$, en agregados radiales de cristales incoloros, colores de interferencia azul y verde del segundo orden, con extinción paralela a ondulante. Se presenta junto con epidota y agregados finos de titanita.

Los opacos se presentan en los planos de clivaje de biotitas en cristales xenomórficos. Llegan a medir hasta de $0,5 \mathrm{~mm}$ y son secundarios.

El apatito se presenta en cristales subidiomórficos hexagonales, incoloros, de 0,1 mm, generalmente asociados a biotitas y opacos.

Los minerales de alteración observados en las placas son: moscovita en láminas incoloras subidiomórficas que se presentan en la matriz con tamaño $0,1 \mathrm{~mm}$; epidota en agregados xenomórficos de relieve alto, como alteración de biotita y caolín a partir de feldespato potásico. 


\section{Geoquímica}

La caracterización litogeoquímica de las Riolitas El Uvo se realizó a partir de los análisis de dos muestras de roca, a las que se les realizó análisis petrográfico.

Los análisis químicos de las muestras se hicieron en los laboratorios del Servicio Geológico Colombiano (Bogotá). Los óxidos mayores y menores se analizaron con un espectrómetro de fluorescencia de rayos X, FRX, Panalytical Axios Mineral para análisis elemental, y la cuantificación de los mayores se realizó en muestra fundida con metaborato y tetraborato de litio, mientras que la de elementos menores se hizo en muestra prensada. En los análisis de elementos traza se usó un espectrómetro de masas con plasma inductivamente acoplado, ICPMS, Perkin Elmer Nexion. La disolución de la muestra se hizo mediante un ataque por pasos utilizando ácidos inorgánicos fuertes $\left(\mathrm{HF}, \mathrm{HNO}_{3}, \mathrm{HClO}_{4} \mathrm{y} \mathrm{HCl}\right)$. El proceso se realizó en sistema abierto, empleando distintas rampas de temperatura y tiempos de calentamiento.

Los resultados de óxidos mayores se presentan en porcentaje en peso (wt\%), y los de elementos traza y tierras raras, en partes por millón (ppm).

Algunos diagramas geoquímicos se generaron con el programa de GCDKit versión 4.0 (Janoušek et al., 2006).

\section{1. Óxidos mayores}

Los resultados de óxidos mayores son similares en las dos muestras, y se exponen en la tabla 2. Los valores de $\mathrm{SiO}_{2}$ en rocas de las Riolitas El Uvo varían entre 75,80\% y 76,81\%; los valores de $\mathrm{Al}_{2} \mathrm{O}_{3}\left(12,68\right.$ y 13,06); el $\mathrm{TiO}_{2}$ es menor de 0,16\%; el MgO está por debajo del 0,21\%; presentan un alto contenido de álcalis $\left(\mathrm{Na}_{2} \mathrm{O}+\mathrm{K}_{2} \mathrm{O}>7 \%\right)$, y la relación $\mathrm{K}_{2} \mathrm{O} / \mathrm{Na}_{2} \mathrm{O}>1$.

Tabla 2. Composición de óxidos mayores en rocas de las Riolitas El Uvo

\begin{tabular}{cccccccccccc}
\hline IGM & $\mathbf{N} \cdot{ }^{\circ}$ campo & $\mathbf{S i O}_{2}$ & $\mathrm{TiO}_{2}$ & $\mathbf{A l}_{2} \mathrm{O}_{3}$ & $\mathrm{Fe}_{2} \mathrm{O}_{3}$ & $\mathbf{M g O}$ & $\mathbf{C a O}$ & $\mathbf{N a}_{2} \mathrm{O}$ & $\mathbf{K}_{2} \mathrm{O}$ & $\mathbf{P}_{2} \mathrm{O}_{5}$ & $\mathbf{L O I}$ \\
\hline 900945 & $\mathrm{MIA}-640$ & 75,80 & 0,15 & 13,06 & 1,01 & 0,21 & 0,65 & 2,62 & 5,45 & 0,026 & 0,95 \\
\hline 900946 & $\mathrm{MIA}-641$ & 76,81 & 0,12 & 12,68 & 0,85 & 0,19 & 0,69 & 3,00 & 4,91 & 0,024 & 0,59 \\
\hline
\end{tabular}

Con el fin de observar posibles modificaciones químicas en las muestras por meteorización o alteración hidrotermal, estas se analizaron en los diagramas de Nesbitt y Young (1984) y de Hughes (1972). En el primero (figura 5A), que sirve para analizar tendencias de meteorización, se observa que las dos muestras están un poco distantes de la composición de riolitas frescas, lo que sugiere modificación química por meteorización. En el segundo, que presenta los campos de rocas con composición ígnea y campos de alteración sódica y potásica (figura 5B), se aprecia que una de las muestras conserva su composición ígnea (IGM900946), mientras que la otra está alterada (IGM900945).
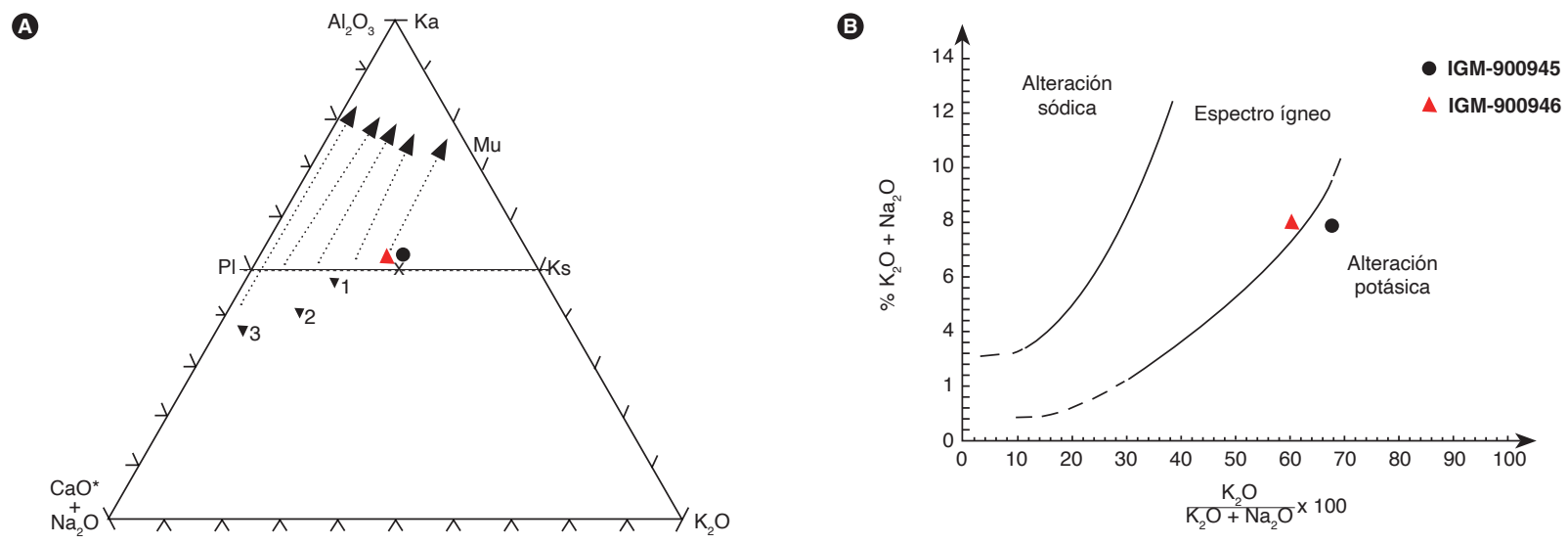

Figura 5. Diagramas para analizar la meteorización y alteración hidrotermal de las muestras de alteración las Riolitas El Uvo.

A) Diagrama de Nesbitt y Young (1984) donde se muestran composiciones de rocas frescas y tendencias de meteorización. B) Diagrama de Hughes (1972), algunos de cuyos campos indican composiciones ígneas y, otros, alteraciones hidrotermales. En la figura 5A, Pl: plagioclasa; Ks: feldespato potásico; Mu: moscovita; Ka: caolinita. 1: composición promedio de riolita; 2: promedio de latita; 3: promedio de basalto 
En el diagrama de Le Bas et al., (1986), las rocas de las Riolitas El Uvo químicamente se localizan en el campo de las riolitas, lo que confirma la clasificación petrográfica (figura 6A), y son de la serie subalcalina. En el diagrama de Peccerillo y Taylor (1976), ambas muestras se ubican en el campo de las rocas calcoalcalinas ricas en potasio, con contenidos de $\mathrm{K}_{2} \mathrm{O}>4,9 \%$ (figura $6 \mathrm{~B}$ ), don-

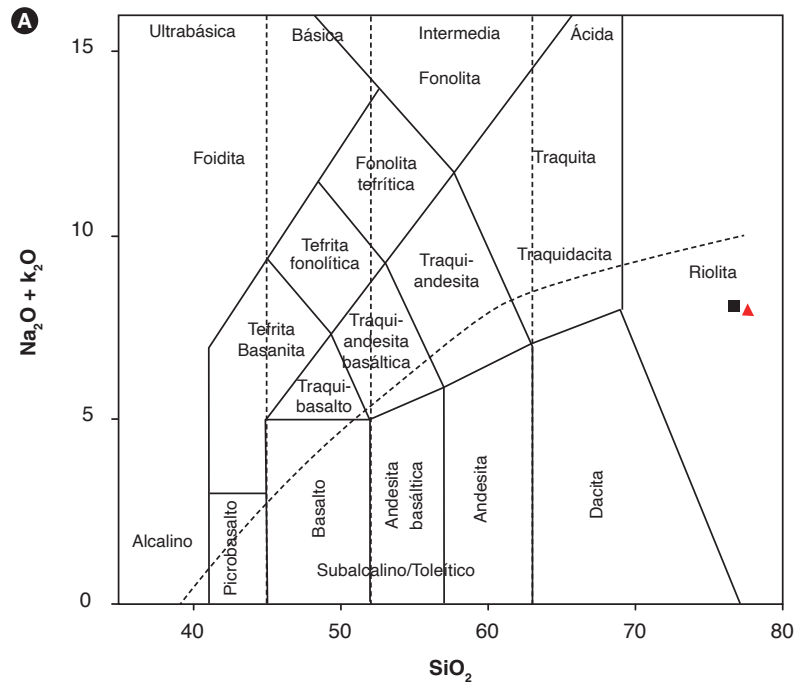

de el contenido de $\mathrm{K}_{2} \mathrm{O}$ de la muestra IGM-900945, que grafica más arriba, puede haber aumentado por la alteración.

En el diagrama de alcalinidad-aluminosidad (Shand, 1943) (figura 6C) se graficó la muestra IGM-900946, que parece conservar más su composición original; esta se ubica en el campo de las rocas peraluminosas.

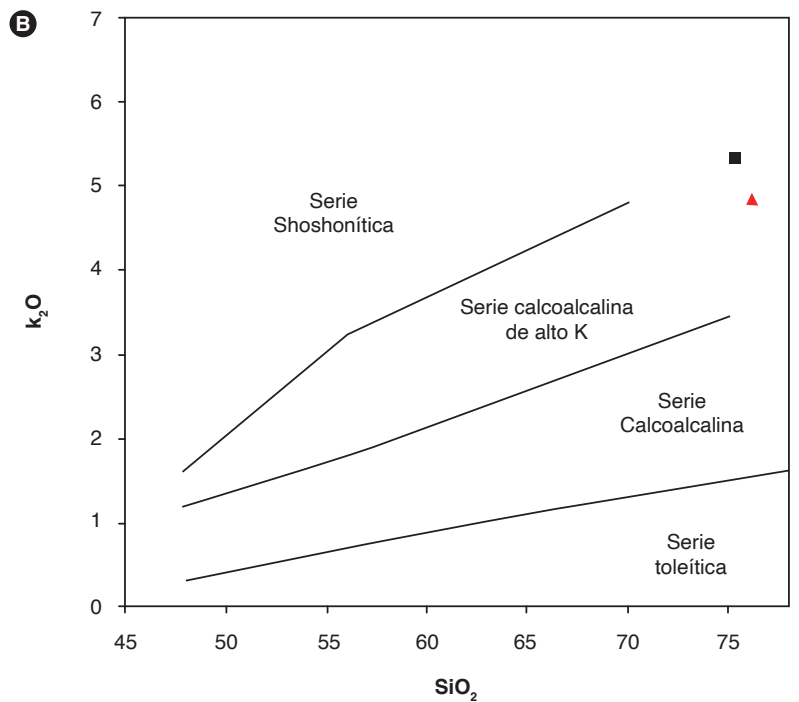

(

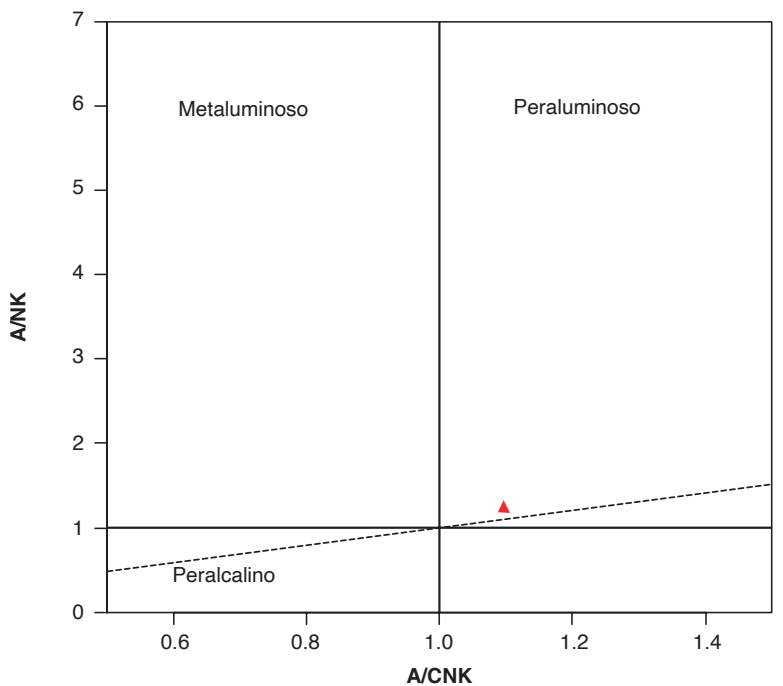




\subsection{Elementos traza y tierras raras}

Los resultados de los análisis de elementos traza y tierras raras presentes en las dos rocas de las Riolitas El Uvo se presentan en la tabla 3 .

Tabla 3. Resultados de elementos traza y tierras raras presentes en rocas de las Riolitas El Uvo

\begin{tabular}{|c|c|c|c|}
\hline Elemento & IGM900945 & IGM900946 & Ld (ppm) \\
\hline $\mathrm{Li}$ & 14,42 & 11,19 & 0,5 \\
\hline $\mathrm{Be}$ & 4,25 & 4,47 & 0,1 \\
\hline Sc & 5,54 & 7,27 & 0,1 \\
\hline V & 11,30 & 12,95 & 0,2 \\
\hline $\mathrm{Cr}$ & 6,49 & 10,53 & 0,5 \\
\hline Co & 14,67 & 20,18 & 0,8 \\
\hline $\mathrm{Ni}$ & 4,65 & 4,18 & 0,5 \\
\hline $\mathrm{Cu}$ & 9,34 & 6,74 & 1 \\
\hline $\mathrm{Zn}$ & 45,91 & 21,20 & 4 \\
\hline $\mathrm{Ga}$ & 17,54 & 16,26 & 0,2 \\
\hline As & 1,22 & 1,35 & 0,4 \\
\hline $\mathrm{Rb}$ & 268,34 & 323,38 & 0,2 \\
\hline $\mathrm{Sr}$ & 111,33 & 69,08 & 1 \\
\hline $\mathrm{Cd}$ & 0,09 & 0,08 & 0,08 \\
\hline Cs & 2,41 & 5,39 & 0,1 \\
\hline $\mathrm{Ba}$ & 330,61 & 160,16 & 1 \\
\hline La & 20,55 & 17,69 & 0,1 \\
\hline $\mathrm{Ce}$ & 36,71 & 33,88 & 0,1 \\
\hline $\operatorname{Pr}$ & 4,59 & 4,24 & 0,1 \\
\hline $\mathrm{Nd}$ & 15,42 & 15,08 & 0,1 \\
\hline $\mathrm{Sm}$ & 2,98 & 2,99 & 0,01 \\
\hline $\mathrm{Eu}$ & 0,50 & 0,33 & 0,01 \\
\hline Gd & 2,23 & 2,24 & 0,01 \\
\hline $\mathrm{Tb}$ & 0,54 & 0,52 & 0,01 \\
\hline Dy & 2,75 & 2,94 & 0,01 \\
\hline $\mathrm{Ho}$ & 0,60 & 0,66 & 0,01 \\
\hline $\mathrm{Er}$ & 2,02 & 2,21 & 0,01 \\
\hline $\mathrm{Tm}$ & 0,32 & 0,36 & 0,01 \\
\hline $\mathrm{Yb}$ & 2,37 & 2,71 & 0,01 \\
\hline Lu & 0,41 & 0,45 & 0,01 \\
\hline $\mathrm{TI}$ & 1,98 & 2,04 & 0,01 \\
\hline $\mathrm{Pb}$ & 23,35 & 26,42 & 2 \\
\hline $\mathrm{Bi}$ & 0,14 & 0,24 & 0,1 \\
\hline Th & 30,89 & 32,06 & 0,1 \\
\hline U & 9,01 & 8,28 & 0 \\
\hline $\mathrm{Zr}$ & 73,60 & 62,10 & 2 \\
\hline $\mathrm{Nb}$ & 13,00 & 18,00 & 2 \\
\hline W & 47,00 & & 8 \\
\hline
\end{tabular}

Ld: límite de detección

El diagrama de elementos de las tierras raras (REE) normalizado al condrito según los valores de Nakamura (1974) muestra en las Riolitas El Uvo un enriquecimiento en tierras raras livianas (LREE) con valores mayores de diez veces el valor del condrito, con un patrón homogéneo que se va empobreciendo progresivamente hacia las tierras raras pesadas (HREE), con un pronunciado declive en Eu (anomalía negativa), y con una tendencia paralela levemente ascendente entre Dy y Lu (figura 7A). La relación $\mathrm{La} / \mathrm{Yb}_{\mathrm{N}}(5,78-4,36)$ representa un patrón de pendiente negativa.

Las dos muestras analizadas tienen anomalía negativa de $\mathrm{Eu}\left(\mathrm{Eu} / \mathrm{Eu}^{*}<1\right)$. Las relaciones $\mathrm{Eu} / \mathrm{Eu}^{*}<1$ y LaN/ $\mathrm{Sm}_{\mathrm{N}}>2$ evidencian un enriquecimiento de tierras raras ligeras con relación a las HREE en todas las muestras (tabla 4$)$.

En el diagrama multielemental normalizado al manto primitivo, con los valores de Sun y McDonough (1989) se aprecia homogeneidad en el comportamiento de ambas muestras, (figura 6B), que presentan enriquecimiento en elementos litófilos incompatibles de alto radio iónico (LILE) Cs, Ba y Th, que indican un patrón geoquímico con afinidad de corteza continental en márgenes convergentes. Las muestras exhiben anomalías positivas de $\mathrm{Rb}$, Th, $\mathrm{U}$ y $\mathrm{K}$, y anomalías negativas de los elementos inmóviles $\mathrm{Nb}, \mathrm{Sr}, \mathrm{P}, \mathrm{Zr}$ y Ti (figura 7B). Las anomalías negativas de Nb, Ti y P son características de ambientes relacionados con subducción.
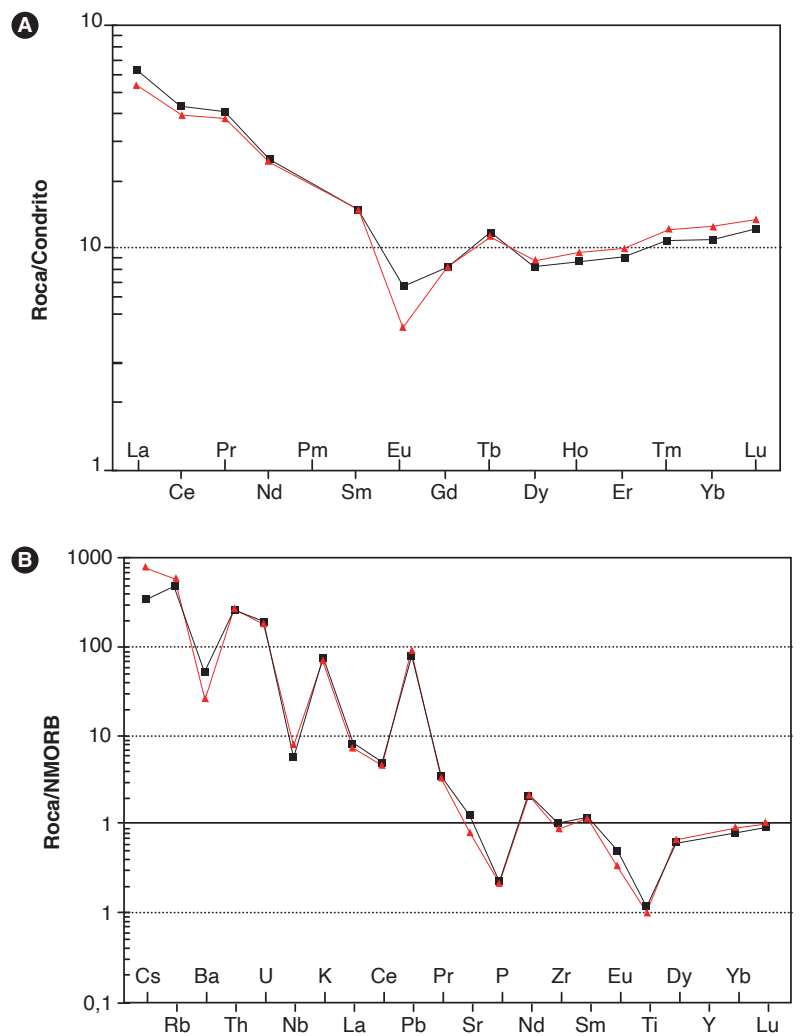

Figura 7. A) Diagrama de REE normalizado respecto a condrito (Nakamura, 1974). B) Diagrama normalizado al NMORB (Sun y McDonough, 1989). 
Tabla 4. Relaciones normalizadas al condrito de Nakamura (1974) de La, Ce, Sm, Eu e Yb en rocas de las Riolitas El Uvo

\begin{tabular}{ccccccccccccc}
\hline IGM & LaN & CeN & SmN & EuN & YbN & Eu/Eu* & LaN/YbN & LaN/SmN & CeN/YbN & CeN/SmN & EuN/YbN & SmN/YbN \\
\hline 900945 & 62,28 & 42,4 & 14,7 & 6,53 & 10,77 & 0,6 & 5,78 & 4,24 & 3,94 & 2,89 & 0,61 & 1,36 \\
\hline 900946 & 53,6 & 39,2 & 14,7 & 4,23 & 12,3 & 0,39 & 4,36 & 3,64 & 3,18 & 2,66 & 0,34 & 1,20 \\
\hline
\end{tabular}

\subsection{Discriminación de ambiente tectónico}

En el diagrama A/CNK/SiO 2 de Frost et al., (2001), la muestra IGM900946 de las Riolitas El Uvo, cuya composición química parece no estar modificada por alteración, grafica en el campo de los magmas tipo I, aunque muy cerca del límite con el campo de los magmas tipo $\mathrm{S}$ (figura $8 \mathrm{~A}$ ). En el diagrama $\mathrm{Th} / \mathrm{Yb}$ vs. $\mathrm{Nb} / \mathrm{Yb}$ (Pearce, 2008) (figura 8B), las rocas corresponden a granitos de arco.
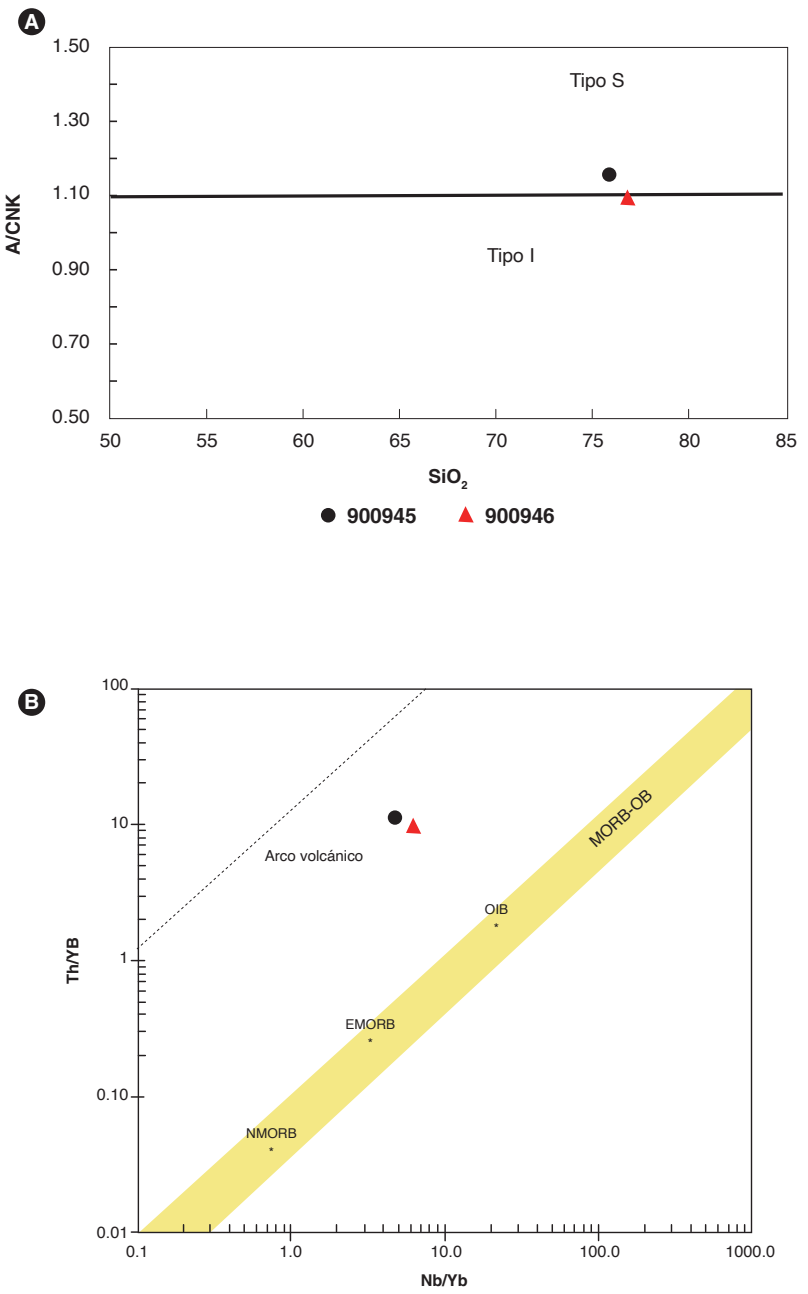

Figura 8. A) Diagrama de Frost et al. (2001) de discriminación de granitoides tipo I y S. B) Diagrama Nb/Yb-Th/Yb (Pearce, 2008).
En el diagrama de discriminación de granitos de Maniar y Piccoli (1989) (figura 9A) las rocas de las Riolitas El Uvo grafican en el campo de los granitos posorogénicos (POG), y en el diagrama de Thiéblemont y Tegyey (1994) las dos muestras se ubican en el campo de los leucogranitos peraluminosos (figura 9B), próxima al campo de las rocas de colisión, campo que también es interpretado como representativo de magmatismo calcoalcalino derivado de la corteza o rocas de arcos generados en cortezas engrosadas (Thiéblemont, 1999).
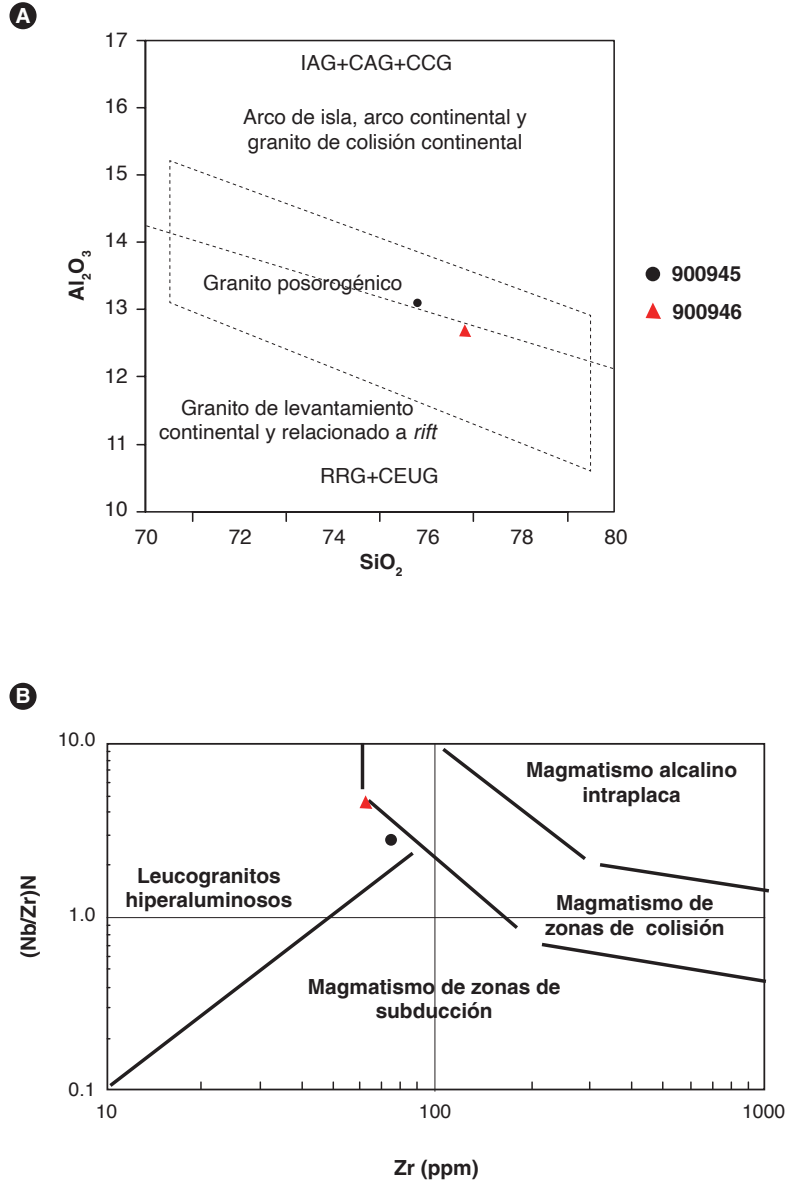

Figura 9. Diagramas discriminantes del ambiente tectónico. A) Diagrama de discriminación de granitos de Maniar y Piccoli (1989). B) Diagrama Nb/Zr vs. Zr de Thiéblemont y Tegyey (1994). 


\section{Posición estratigráfica y edad}

Las Riolitas El Uvo intruyen el Batolito de Mogotes, cuyas edades $\mathrm{U} / \mathrm{Pb}$ van de 202,5 $\pm 1,3$ a 188,9 $\pm 1,3 \mathrm{Ma}$ (Correa Martínez et al., 2020). De las Riolitas El Uvo, otros autores no han presentado edades. En este trabajo se realizó la datación de una muestra colectada sobre la carretera Macanal-El Uvo, plancha 136, Málaga, a escala 1:1 00.000. La muestra tiene descripción petrográfica y análisis litogeoquímico. Su localización se presenta en la figura 1 y en la tabla 5. La separación de los circones se realizó en el Laboratorio Químico del Servicio Geológico Colombiano, sede Medellín, utilizando separación hidrodinámica, magnética y lupa binocular para el montaje de los circones sobre una cinta de doble faz adherida a un vidrio de $5 \times 5 \mathrm{~cm}$.

La datación se hizo a partir de un concentrado de circones obtenido del saprolito de la muestra MIA 641, de la cual se extrajeron 52 circones. Los análisis isotópicos se llevaron a cabo en el Laboratorio de Geocronología del Servicio Geológico Colombiano, en Bogotá, mediante el método de ablación laser acoplada a espectrometría de masas con fuente de plasmas de acoplamiento inductivo (LA-ICP-MS, por sus siglas en inglés). A la muestra se le realizó un análisis estadístico para mejorar el rango de confiabilidad de la edad. Para ello se tuvo en cuenta la relación $\left.\left[\left({ }^{207} \mathrm{~Pb} /{ }^{235} \mathrm{U}\right)-\left({ }^{206} \mathrm{~Pb} /{ }^{238} \mathrm{U}\right) /{ }^{206} \mathrm{~Pb} /{ }^{238} \mathrm{U}\right)\right]$ y se eliminaron los datos con valores discordantes $>5 \%$ y con discordancia inversa $<-5 \%$. El gráfico de concordia e histogramas se elaboraron en el software de Isoplot/Ex vers. 3.75-4.15 (Ludwig, 2008). Los resultados se presentan en el anexo 1.

Tabla 5. Resultado de geocronología U/Pb correspondiente a la muestra MIA-641 de Riolitas EI Uvo

\begin{tabular}{ccccccc}
\hline IGM & N. $^{\circ}$ campo & N & E & Plancha & Clasificación & Edad \\
\hline 900946 & MIA-641 & 1206200 & 1141207 & 136 & Riolita porfídica & $197,5 \pm 1,5$ \\
\hline
\end{tabular}

Los circones de la muestra MIA 641 son cristales con formas prismáticas euhedrales, transparentes y de color pardo, con inclusiones de opacos, presentan tamaños entre $30 \mu \mathrm{m}$ y $200 \mu \mathrm{m}$. En imágenes de catodoluminiscencia (CL) se observan zonamientos oscilatorios. La ablación en esta muestra se hizo en los extremos y, en algunos cristales, en el límite entre el núcleo zonado y los bordes (figura 10), para explorar posibles sobrecrecimientos y edades heredadas.
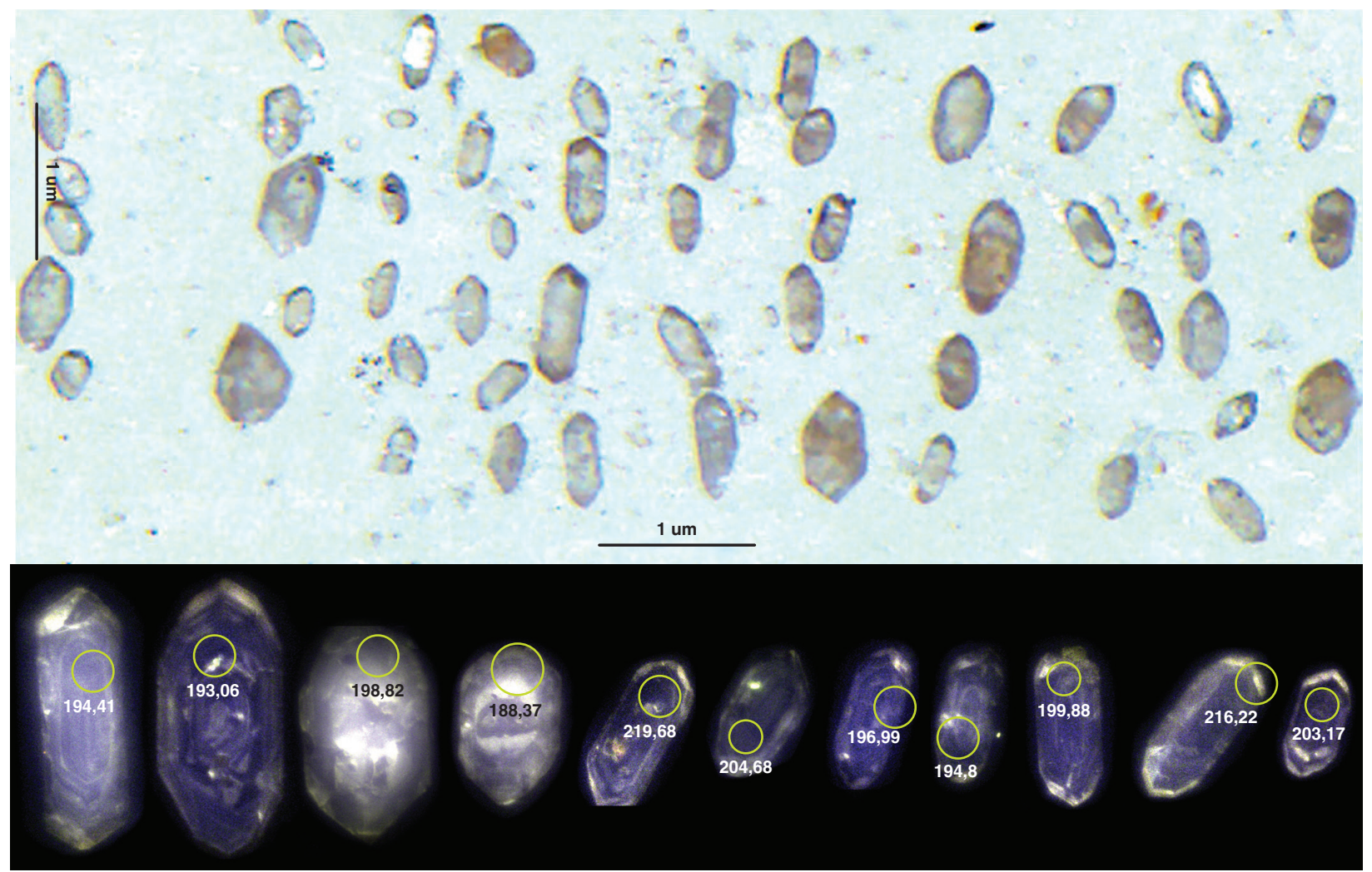

Figura 10. Imágenes de catodoluminiscencia de circones de la muestra MIA 641.

En el círculo, los puntos de análisis de las edades $\mathrm{U} / \mathrm{Pb}$ y el número del punto. Los números externos corresponden a la edad de los cristales 
En la muestra se halla una edad heredada antigua del Mesoproterozoico (1168 $26 \mathrm{Ma})$. El resto de datos corresponden a edades que oscilan entre $\sim 220 \mathrm{Ma}$ Triásico tardío (Noriense) y $\sim 187$ Ma Jurásico temprano (Pliensbachiense). En el gráfico de densidad de probabilidad y en el diagrama de concordia (figura 11 A y B) se observan dos poblaciones de datos, la principal con la mayoría de ellos, con edades de entre 198 y 200 Ma; las otras dos corresponden a edades de 216 a 219 Ma.

El cálculo de la edad media ponderada a partir de 38 datos con edades entre 184,4 y 205,41 Ma arroja una edad de 197,5 \pm 1,5 Ma con MSWD 4,0 (figura $11 \mathrm{C}$ ), que se interpreta como la posible edad de cristalización de la roca.

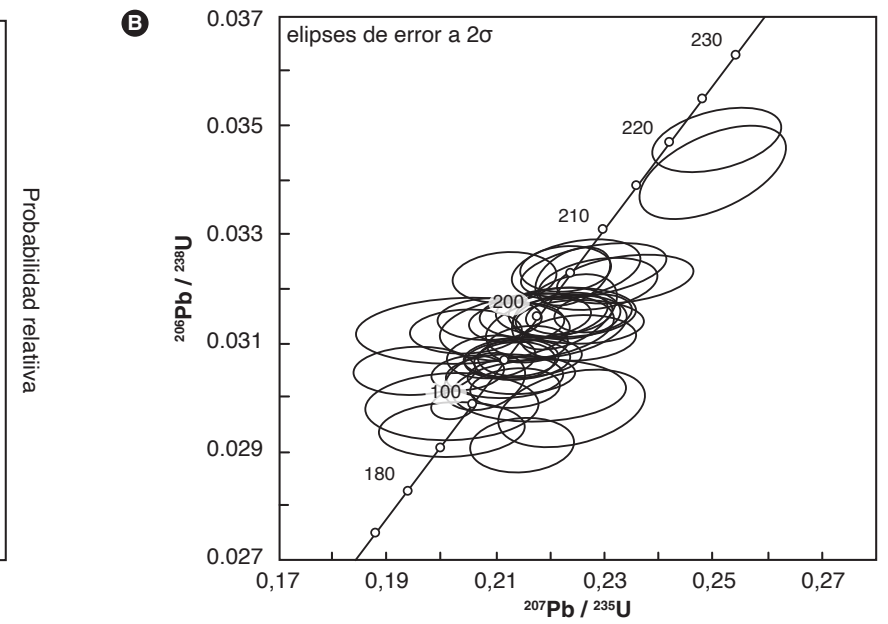

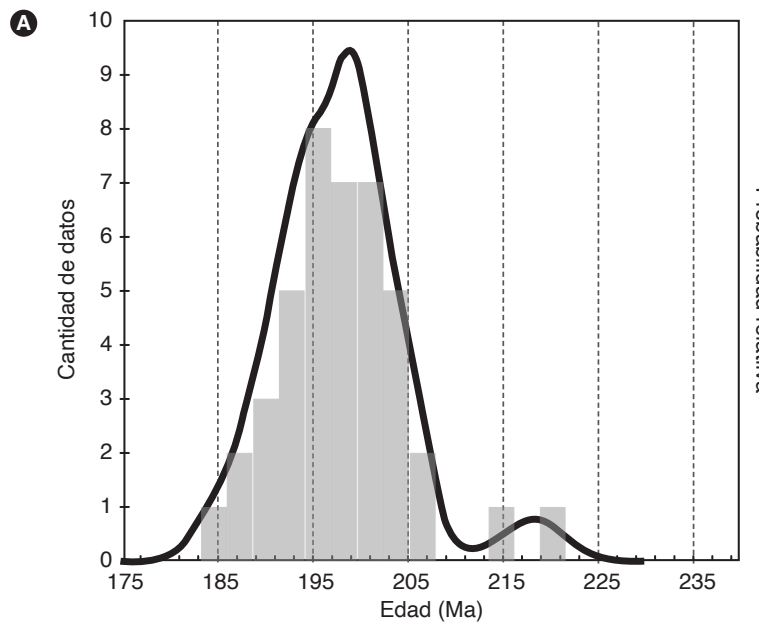

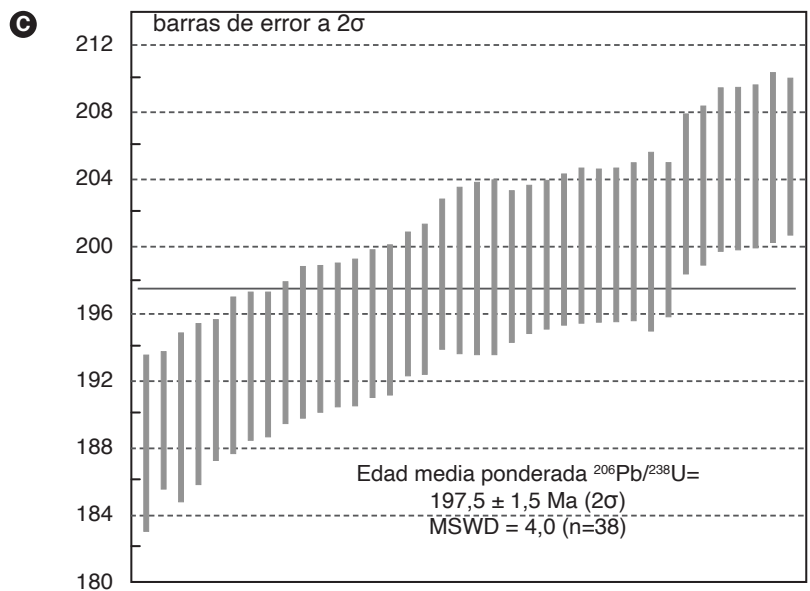

Figura 11. A) Diagrama de probabilidad en circones de la muestra MIA-641 (IGM 900946). B) Diagrama de concordia. C) Cálculo de la edad media ponderada. 


\section{Correlaciones}

Las Riolitas El Uvo se correlacionan composicionalmente con las Riolitas del Alto de Los Cacaos y tienen semejanza, aunque también algunas diferencias, con la Riolita de San Joaquín y los granófidos del Granito de Pescadero (figura 12). En cuanto a la edad (197,5 $\pm 1,5$ Ma), la máxima casi se traslapa con la mínima de las Riolitas del Alto Los Cacaos (201,6 $\pm 2,1$, Correa Martínez et al., 2020B) y de San Joaquín $(201 \pm 2,1)$ (Rodríguez, Arango et al., $2018 \mathrm{8}$ ), y su edad mínima casi se traslapa con la máxima de los granófidos del Granito de Pes- cadero (1 92,9 $\pm 2,0 \mathrm{Ma}$ ) (Zapata et al., 2020). Las Riolitas de El Uvo también se pueden correlacionar con diques que intruyen granodioritas de la unidad Monzogranito de Rionegro (196,6 $\pm 1,8 \mathrm{Ma}$ ) (Arango et al., 2016), y en edad, con algunos pulsos magmáticos del Batolito de Mogotes (202,5 $\pm 1,3$ a 193,7 $\pm 1,3 \mathrm{Ma}$ ) (Correa Martínez et al., 2020a), Monzogranito de Santa Bárbara (196,8 $\pm 2,0$ a 192,0 $\pm 1,1 \mathrm{Ma}$ ) (Rodríguez et al., $2018 \mathrm{~b})$ y Monzogranito de La Corcova (199,5 $\pm 4,6$ a $192,5 \pm 2,6$ Ma) (Rodríguez et al., 2016).

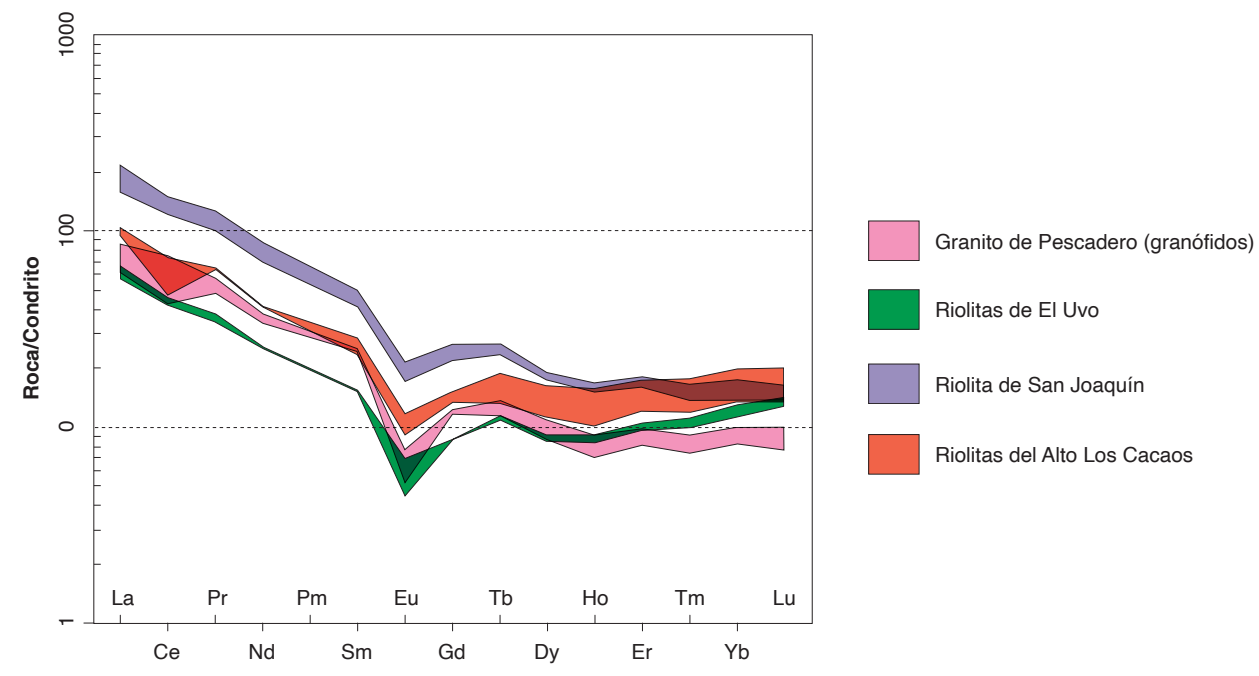

Figura 12. Comparación de los patrones de REE de muestras de las unidades Riolitas de El Uvo, Riolitas del Alto Los Cacaos, Granito de Pescadero y Riolita de San Joaquín, normalizados a los valores de Boynton (1984).

Fuente de datos: este trabajo; Correa Martínez et al. (2020B); Zapata et al. (2020); Rodríguez et al. (2018a)

\section{Localidad tipo}

Se propone como localidad tipo para las Riolitas El Uvo la carretera vereda Santa Fe-El Uvo, municipio de San Joaquín, en las planchas 136, Málaga, y 152, Soatá, a escala 1:100.000 del Ingeominas. En este sector la unidad presenta esporádicos afloramientos de fácil acceso.

\section{Génesis}

Las características macroscópicas y microscópicas de las Riolitas El Uvo, tales como textura porfídica con matriz microcristalina felsítica a micrográfica, indican un emplazamiento subvolcánico poco profundo del cuerpo, que se dio en rocas plutónicas del Batolito de Mogotes.
Las Riolitas El Uvo presentan valores de $\mathrm{SiO}_{2}$ entre $75,8 \%$ y 76,8\%,\%; presentan un alto contenido de álcalis $\left(\mathrm{Na}_{2} \mathrm{O}+\mathrm{K}_{2} \mathrm{O}>7 \%\right)$ y relaciones $\mathrm{K}_{2} \mathrm{O} / \mathrm{Na}_{2} \mathrm{O}>1$, por lo que químicamente se clasifican como riolitas de la serie calcoalcalina alta en $\mathrm{K}$. Los contenidos altos de $\mathrm{K}_{2} \mathrm{O}$ de una de las muestras se deben a alteración hidrotermal que modificó su composición química.

Las Riolitas El Uvo muestran enriquecimiento en tierras raras livianas (LREE) con valores diez veces mayores que los del condrito, empobrecidas en tierras raras pesadas (HREE) y con anomalía negativa Eu. Las Riolitas El Uvo tienen un patrón semejante al de arco continental, con anomalías positivas de $\mathrm{Rb}$, Th, $\mathrm{U}, \mathrm{Pb}, \mathrm{y}$ negativas de Ba, Nb, Sr, P y Ti. 
Los valores altos de los elementos Cs y Th indican afinidad con corteza continental (márgenes convergentes), donde abundan estos elementos altamente incompatibles. Son granitos en la transición tipo I a tipo S, peraluminosos, posiblemente posorogénicos.

Las Riolitas El Uvo están relacionadas genéticamente con otros cuerpos subvolcánicos de la región, tales como las Rilitas del Alto Los Cacaos, la Riolita de San Joaquín y los granófidos presentes en el Granito de Pescadero, y deben hacer parte del mismo complejo volcánico, donde posiblemente se cristalizaron primero las unidades Riolitas del Alto Los Cacaos y Riolita de San Joaquín, después las Riolitas El Uvo y finalmente los granófidos del Granito de Pescadero.

\section{Recursos minerales}

Las rocas porfídicas y su alteración potásica, identificada químicamente en una de las muestras (IGM-900945), sugieren que la unidad tiene potencial de minerales metálicos. Para evaluar si las rocas pueden estar mineralizadas se graficaron las dos muestras en el diagrama de Rb vs. Ba (figura 13), adaptado por El-Sheshtawi et al., 1999) del diagrama original de Mason (1966). En dicho diagrama solo se visualiza una de las muestras, la IGM-900945, porque la otra queda por fuera de este, pero si se extendiese el eje de las abscisas, la muestra IGM900946 graficaría en el campo de los granitos mineralizados (Rb: 323 ppm; Ba: 160 ppm). Así que las muestras de las Riolitas El Uvo corresponden a rocas fértiles (potencialmente mineralizadas con minerales metálicos).

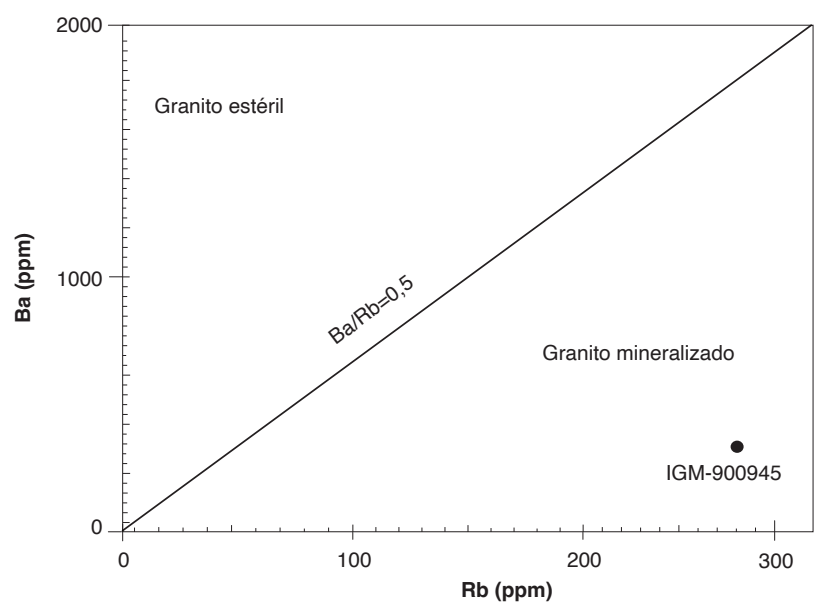

Figura 13. Diagrama de variación de Rb versus Ba en roca total (Mason, 1966, adaptado por El-Sheshtawi et al., 1999).

Fuente de datos: este trabajo
Otro potencial de las Riolitas El Uvo sería como material para agregados o piedra ornamental. Sin embargo, para definir este potencial son necesarios estudios de caracterización de los materiales.

\section{Conclusiones}

La unidad Riolitas El Uvo se define como una nueva unidad geológica del Macizo de Santander, que contiene riolitas hipoabisales con textura porfídica, lo que sugiere que pudieron haber cristalizado a niveles poco profundos de la corteza terrestre.

Las Riolitas El Uvo son subalcalinas de la serie calcoalcalina alta en $\mathrm{K}$, con alteración local hidrotermal, y se generaron a partir de magmas tipo I, quizá en la transición hacia tipo S, peraluminoso. Las rocas de esta unidad exhiben características geoquímicas propias de ambientes relacionados con subducción y con potencial mineral de ser un cuerpo mineralizado probablemente con minerales metálicos.

La edad U/Pb en circones obtenida en una de las muestras de las Riolitas El Uvo es de 197,5 \pm 1,5 Ma, que se interpreta como la edad de cristalización de la roca.

La unidad se puede correlacionar con otros cuerpos subvolcánicos de la región, tales como las Riolitas del Alto Los Cacaos, la Riolita de San Joaquín y los granófidos del Granito de Pescadero, donde, según las edades, la cristalización de las Riolitas El Uvo siguió la cristalización de los dos primeros cuerpos y antecedió a la de los granófidos de Pescadero.

\section{Referencias}

Arango, M. I., Rodríguez, G., Zapata, G. y Correa M., A. M. (2016). Catálogo de unidades litoestratigráficas de Colombia. Monzogranito de Rionegro, cordillera Oriental, Departamento Santander. Bogotá: Servicio Geológico Colombiano.

Boynton, W. V. (1984). Cosmochemistry of the rare earth elements: Meteorite studies. En Developments in geochemistry (vol. 2, pp. 63-114). Elsevier.

Clavijo, J., Mantilla, F. L. C., Pinto, J., Bernal, L. y Pérez, A. (2008). Evolución geológica de la serranía de San Lucas, norte del valle medio del Magdalena y noroeste de la cordillera Oriental. Boletín de Geología, 30 (1), 45-62.

Correa Martínez, A. M., Rodríguez, G., Arango, M. I., Zapata, G. y Bermúdez, J. G. 2020a. Batolito de Mogotes. En Catálogo de las unidades litoestratigráficas de 
Colombia: Macizo de Santander. Vol. 1. Bogotá: Servicio Geológico Colombiano.

Correa Martínez, A. M., Rodríguez, G., Bermúdez, J. G., Arango, M. I. y Zapata, G. 2020b. Riolitas del Alto Los Cacaos. En Catálogo de las unidades litoestratigráficas de Colombia: Macizo de Santander. Vol. 1.Bogotá: Servicio Geológico Colombiano.

El-Sheshtawi, Y. A., Youssef, F., Ammar, F. A., Hassaan, M. M., Sakr, S. M. (1999). Petrography and geochemistry of some granites and their metavolcanic country rocks in the Central Eastern Desert, Egypt. The proceeding of $1^{\text {st }}$ Seminar of Nuclear Raw Material and their Technology, Cairo, Egypt, 1-3.

Forero, A. (1990). The basement of the Eastern Cordillera, Colombia: An allochthonous terrane in Northwestern South America. Journal of South American Earth Sciences, 3 (2-3), 141-151. https://doi. org/10.101 6/0895-9811(90)90026-W

Frost, R. B., Barnes, C. G., Collins, W. J., Arculus, R. J., Ellis, D. J. y Frost, C. D. (2001). A geochemical classification for granitic rocks. Journal of Petrology, 42 (11), 2033-2048. https://doi.org/10.1 093/petrology/42.11.2033

García, C., Ríos, C. (1 999). Metamorfismo y metalogenia asociada del Macizo de Santander, cordillera Oriental, Colombia. Informe final, Proyecto de Investigación 1102-05-083-95 Colciencias-Universidad Industrial de Santander, Bucaramanga.

Goldsmith, R., Marvin, R. F. y Mehnert, H. H. (1971). Radiometric ages in the Santander Massif, Eastern Cordillera, and Colombian Andes. U.S. Geological Survey Professional Paper, 750-D, D44-D49.

Hughes, C. J. (1972). Spilites, keratophyres and the igneous spectrum. Geological Magazine, 109 (6), 513527. https://doi.org/10.101 7/S0016756800042795

International Subcommission on Stratigraphic Classification. (1987). Stratigraphic classification and nomenclature of igneous and metamorphic rock bodies. GSA Bulletin, 99 (3), 440-442. https://doi.org/10.1130/001 6-7606(1987)99<440:SCANOI >2.0. $\mathrm{CO} ; 2$

International Subcommission on Stratigraphic Classification. (1994). International Stratigraphic Guide. A guide to stratigraphic classification, terminology and procedure. (2. ${ }^{\mathrm{a}}$ ed.) A. Salvador (ed.). Boulder: International Union of Geological Sciences y Geological Society of America.
Irvine, T. N. y Baragar, W. R. A. (1971). A guide to the chemical classification of the common volcanic rocks. Canadian Journal of Earth Sciences, 8 (5), 523548. https://doi.org/10.1139/e71-055

Janoušek, V., Farrow, C. M. y Erban, V. (2006). Interpretation of whole-rock geochemical data in igneous geochemistry: Introducing geochemical data toolkit (GCDkit). Journal of Petrology, 47 (6), 1255-1259. https://doi.org/1 0.1093/petrology/egl013

Le Bas, M. J., Le Maitre, R. N., Streckeisen, A. y Zanettin, B. (1986). A chemical classification of volcanic rock based on total silica diagram. Journal of Petrology, 27 (3), 745750. https://doi.org/10.1093/petrology/27.3.745

Leal Mejía, H. (2011). Phanerozoic gold metallogeny in the Colombian Andes: A tectono-magmatic approach. (Ph. D. thesis). Universitat de Barcelona.

Ludwig, K. (2008). Isoplot version 4.15: A geochronological toolkit for Microsoft Excel. Berkeley Geochronology Center, special publication n. ${ }^{\circ} 4$.

Maniar,P.D.yPiccoli,P.M.(1989).Tectonicdiscrimination of granitoids. GSA Bulletin, 101 (5), 635-643. https:// doi.org/10.1130/0016-7606(1989)101<0635:T$\mathrm{DOG}>2.3 . \mathrm{CO} ; 2$

Mantilla, L. C., Bissig, T., Valencia, V.y Hart, C. (2013). The magmatic history of the Vetas-California mining district, Santander Massif Eastern Cordillera, Colombia. Journal of South American Earth Sciences, 45, 235-249. https://doi.org/10.1016/j.jsames.2013.03.006

Mason, B. (1966). Principles of geochemistry (3. $\stackrel{\text { a }}{\text { ed.). }}$ New York: John Wileys \& Sons.

Nakamura, N. (1 974). Determination of REE, Ba, Fe, Mg, $\mathrm{Na}$ and $\mathrm{K}$ in carbonaceous and ordinary chondrites. Geochimica et Cosmochimica Acta, 38 (5), 757-775. https://doi.org/10.1016/001 6-7037(74)90149-5

Nesbitt, H. W. y Young, G. M. (1984). Prediction of some weathering trends of plutonic and volcanic rocks based on thermodynamic and kinetic considerations. Geochimica et Cosmochimica Acta, 48 (7), 1523-1534. https://doi.org/10.1016/00167037(84)90408-3

Ordóñez Cardona, O., Restrepo Álvarez, J. J. y Pimentel, M. M. (2006). Geochronological and isotopical review of pre-Devonian crustal basement of the Colombian Andes. Journal of South American Earth Sciences, 21 (4), 372 y 382. https://doi.org/1 0.1016/j. jsames.2006.07.005 
Pearce, J. A. (2008). Geochemical fingerprinting of oceanic basalts with applications to ophiolite classification and the search for Archean oceanic crust. Lithos, 100 (1-4), 14-48. https://doi.org/10.1016/j. lithos.2007.06.016

Peccerillo, A. y Taylor, T. S. (1976). Geochemistry of Eocene calc-alkaline volcanic rocks from Kastamonu area, Northern Turkey. Contributions to Mineralogy and Petrology, 58, 63-81. https://doi.org/10.1007/ BF00384745

Ríos, C., García, C. y Takusa, A. (2003). Tectono-metamorphic evolution of the Silgara Formation metamorphic rocks in the Southwestern Santander Massif, Colombian Andes. Journal of South American Earth Sciences, 16 (2), 133-154. https://doi. org/10.1016/S0895-9811(03)00025-7

Rodríguez, G., Correa M., A. M., Zapata, G. y Arango, M. I. (2016). Catálogo de unidades litoestratigráficas de Colombia. Monzogranito de La Corcova. Medellín: Servicio Geológico Colombiano.

Rodríguez, G., Zapata, G., Correa M., A. M. y Arango, M. I. (2017). Caracterización petrográfica, química y geocronológica del magmatismo triásico-jurásico del Macizo de Santander, Colombia. Resumen XVI Congreso Colombiano de Geología y III Simposio de Exploradores. Santa Marta.

Rodríguez, G., Arango, M. I., Correa, M., A. M. y Zapata, G. (2018a). Catálogo de unidades litoestratigráficas de Colombia. Riolita de San Joaquín. Medellín: Servicio Geológico Colombiano.

Rodríguez, G., Zapata, G., Arango, M. I. y Correa M., A. M. (2018b). Catálogo de unidades litoestratigráficas de Colombia. Monzogranito de Santa Bárbara. Medellín: Servicio Geológico Colombiano.

Shand, S. J. (1943). Eruptive rocks: Their genesis, composition, classification, and their relation to ore-deposits with a chapter on meteorite. New York: John Wiley \& Sons.

Streckeisen, A. L. (1978). IUGS Subcommission on the Systematics of Igneous Rocks. Classification and nomenclature of volcanic rocks, lamprophyres, carbonatites and melilite rocks. Recommendations and suggestions. Neues Jahrbuch für Mineralogie, Abhandlungen (141), 1-14.

Sun,S.yMcdonough,W.(1989).Chemicalandisotopicsystematicsofoceanic basalts:Implications formantlecomposition and processes. Geological Society of London,
Special Publication, 42, 313-345. https:/doi.org/ 10.1144/GSL.SP.1989.042.01.19

Thiéblemont, D. (1999). Discrimination entre magmatismes calco-alcalins mantellique et crustal: l'exemple des Andes. Comptes Rendus de l'Académie des Sciences-Series IIA-Earth and Planetary Science, 329 (4), 243-250. https://doi.org/10.1016/S1 251 $8050(99) 80242-0$

Thiéblemont, D. y Tegyey, M. (1994). Une discrimination géochimique des roches différenciées témoin de la diversité d'origine et de situation tectonique des magmas calco-alcalins. Comptes Rendus Academic Scientific du Paris, 31 9, serie II, 87-94.

Van der Lelij, R. (2013). Reconstructing North-Western Gondwana with implications for the evolution of the lapetus and Rheic Oceans: A geochronological, thermochronological and geochemical study. (Thése de doctorat). Univ. Genéve, n. ${ }^{\circ} 4581$.

Van der Lelij, R., Spikings, R. y Mora, A. (2016). Thermochronology and tectonics of the Mérida Andes and the Santander Massif, NW South America. Lithos, 248-251, 220-239. https://doi.org/10.1016/j.lithos.2016.01.006

Vargas, R., Arias, A., Jaramillo, L. y Téllez, N. (1987). Geología de la plancha 152, Soatá. Escala 1:100.000, mapa, versión digital 2009. Bogotá: Ingeominas.

Vargas, R., Arias, A., Jaramillo, L. y Téllez, N. (1981). Geología de las planchas 136, Málaga, y 152, Soatá, cuadrángulo I-13. Escala 1:100.000, Memoria explicativa. Boletín Geológico, 24 (3).

Vargas, R., Arias, A., Jaramillo, L. y Téllez, N. (1984). Geología de la plancha 136, Málaga. Mapa, escala: 1:100.000. Versión digital 2009. Bogotá: Ingeominas.

Ward, D., Goldsmith, R., Cruz, J. y Restrepo, H. (1973). Geología de los cuadrángulos H-12, Bucaramanga, y H-13, Pamplona. Boletín Geológico, 21 (1-3), 132.

Zapata, G., Correa Martínez, A.M., Rodríguez, G. y Arango, M.I. 2020. Catálogo de unidades litoestratigráficas de Colombia. Granito de Pescadero. Bogotá: Servicio Geológico Colombiano.

Zuluaga, C. A., Amaya, S., Urueña, C. y Bernet, M. (2017). Migmatization and low-pressure overprinting metamorphism as record of two pre-Cretaceous tectonic episodes in the Santander Massif of the Andean basement in Northern Colombia (NW South America). Lithos, 274-275, 123-146. https:// doi.org/10.1016/j.lithos.2016.12.036 


\section{ANEXO A}

\begin{tabular}{|c|c|c|c|c|c|c|c|c|c|c|c|c|c|c|c|c|}
\hline Análisis & $\begin{array}{c}U \\
\text { (ppm) }\end{array}$ & $\begin{array}{c}\text { Th } \\
\text { (ppm) }\end{array}$ & Th/U & $\begin{array}{l}{ }^{207} \mathrm{~Pb} / \\
{ }^{206} \mathrm{~Pb}\end{array}$ & $\pm 2 \sigma$ & $\begin{array}{l}{ }^{207} \mathrm{~Pb} / \\
{ }^{235} \mathrm{U}\end{array}$ & $\pm 2 \sigma$ & $\begin{array}{l}{ }^{206} \mathrm{~Pb} / \\
{ }^{238} \mathrm{U}\end{array}$ & $\pm 2 \sigma$ & $\begin{array}{l}\text { Correlación } \\
\text { errores }\end{array}$ & $\begin{array}{l}{ }^{206} \mathrm{~Pb} /{ }^{238} \mathrm{U} \\
\text { edad (Ma) }\end{array}$ & $\pm 2 \sigma$ & $\begin{array}{l}{ }^{207} \mathrm{~Pb} /{ }^{235} \mathrm{U} \\
\text { edad (Ma) }\end{array}$ & $\pm 2 \sigma$ & $\begin{array}{l}{ }^{207} \mathrm{~Pb} / 206 \mathrm{~Pb} \\
\text { edad (Ma) }\end{array}$ & $\pm 2 \sigma$ \\
\hline MIA_641_46 & 658 & 371 & 0,6 & 0,05310 & 0,00190 & 0,21480 & 0,00780 & 0,02914 & 0,0004 & 0,11542 & 184,4 & 4,5 & 199,1 & 6,5 & 319,0 & 76,0 \\
\hline MIA_641_50 & 302 & 119,1 & 0,4 & 0,04870 & 0,00290 & 0,20200 & 0,01100 & 0,02942 & 0,00041 & 0,10000 & 187,2 & 4,6 & 184,6 & 9,2 & 150,0 & 100,0 \\
\hline MIA_641_2 & 634 & 256 & 0,4 & 0,05410 & 0,00240 & 0,22400 & 0,01100 & 0,02981 & 0,00058 & 0,33463 & 188,4 & 5,3 & 202,1 & 8,7 & 330,0 & 85,0 \\
\hline MIA_641_40 & 3.230 & 7.140 & 2,2 & 0,04958 & 0,00085 & 0,20230 & 0,00330 & 0,02987 & 0,00021 & 0,18596 & 189,8 & 4,0 & 186,8 & 2,8 & 174,0 & 38,0 \\
\hline MIA_641_7 & 219 & 232 & 1,1 & 0,04860 & 0,00300 & 0,20200 & 0,01300 & 0,02985 & 0,0005 & 0,05909 & 189,9 & 5,0 & 184,0 & 11,0 & 110,0 & 110,0 \\
\hline MIA_641_45 & 247 & 423 & 1,7 & 0,05300 & 0,00330 & 0,21800 & 0,01300 & 0,03014 & 0,00046 & 0,07354 & 190,7 & 4,8 & 199,0 & 11,0 & 300,0 & 120,0 \\
\hline MIA_641_1 & 688 & 842 & 1,2 & 0,05080 & 0,00160 & 0,21360 & 0,00680 & 0,03019 & 0,00029 & 0,13259 & 191,5 & 4,2 & 197,5 & 5,5 & 216,0 & 63,0 \\
\hline MIA_641_22 & 1.304 & 3.570 & 2,7 & 0,04990 & 0,00140 & 0,20800 & 0,00610 & 0,0303 & 0,00041 & 0,26945 & 192,4 & 4,6 & 192,3 & 5,2 & 188,0 & 56,0 \\
\hline MIA_641_13 & 424 & 314 & 0,7 & 0,05070 & 0,00210 & 0,21160 & 0,00880 & 0,03041 & 0,00032 & 0,06350 & 192,9 & 4,4 & 194,1 & 7,3 & 230,0 & 82,0 \\
\hline MIA_641_14 & 542 & 505 & 0,9 & 0,05070 & 0,00200 & 0,21470 & 0,00820 & 0,03043 & 0,0003 & 0,12047 & 193,1 & 4,3 & 196,3 & 6,8 & 228,0 & 78,0 \\
\hline MIA_641_21 & 1.270 & 2.570 & 2,0 & 0,04880 & 0,00130 & 0,20490 & 0,00550 & 0,03047 & 0,00026 & 0,21958 & 193,8 & 4,2 & 188,8 & 4,7 & 138,0 & 55,0 \\
\hline MIA_641_30 & 483 & 516 & 1,1 & 0,04720 & 0,00220 & 0,19510 & 0,00900 & 0,03051 & 0,00035 & 0,08628 & 194,4 & 4,5 & 180,2 & 7,6 & 71,0 & 85,0 \\
\hline MIA_641_29 & 803 & 962 & 1,2 & 0,05110 & 0,00170 & 0,21260 & 0,00690 & 0,03069 & 0,0003 & 0,04561 & 194,6 & 4,3 & 195,8 & 5,8 & 240,0 & 69,0 \\
\hline MIA_641_23 & 903 & 1.350 & 1,5 & 0,05130 & 0,00170 & 0,21530 & 0,00690 & 0,03073 & 0,00027 & 0,02419 & 194,8 & 4,3 & 197,2 & 5,8 & 226,0 & 66,0 \\
\hline MIA_641_28 & 582 & 672 & 1,2 & 0,05120 & 0,00200 & 0,21520 & 0,00870 & 0,03075 & 0,0003 & 0,16742 & 195,0 & 4,3 & 196,6 & 7,3 & 241,0 & 78,0 \\
\hline MIA_641_38 & 853 & 848 & 1,0 & 0,04960 & 0,00160 & 0,20920 & 0,00660 & 0,03077 & 0,00032 & 0,10171 & 195,5 & 4,4 & 192,1 & 5,5 & 189,0 & 63,0 \\
\hline MIA_641_47 & 743 & 492 & 0,7 & 0,04950 & 0,00150 & 0,21410 & 0,00660 & 0,0308 & 0,00033 & 0,16701 & 195,7 & 4,5 & 196,7 & 5,6 & 175,0 & 61,0 \\
\hline MIA_641_8 & 673 & 691 & 1,0 & 0,05050 & 0,00150 & 0,21600 & 0,00600 & 0,03099 & 0,00027 & 0,11387 & 196,6 & 4,3 & 198,4 & 5,1 & 208,0 & 59,0 \\
\hline MIA_641_5 & 506 & 575 & 1,1 & 0,05210 & 0,00210 & 0,22520 & 0,00860 & 0,03111 & 0,00033 & 0,10000 & 197,0 & 4,5 & 205,5 & 7,2 & 261,0 & 78,0 \\
\hline MIA_641_24 & 226 & 371 & 1,6 & 0,04800 & 0,00380 & 0,20400 & 0,01600 & 0,03123 & 0,0005 & 0,07667 & 198,8 & 5,2 & 187,0 & 14,0 & 140,0 & 130,0 \\
\hline MIA_641_37 & 679 & 764 & 1,1 & 0,04930 & 0,00210 & 0,20410 & 0,00810 & 0,03123 & 0,00032 & 0,08089 & 198,4 & 4,5 & 188,7 & 6,7 & 160,0 & 79,0 \\
\hline MIA_641_44 & 744 & 688 & 0,9 & 0,05020 & 0,00210 & 0,22010 & 0,00960 & 0,0313 & 0,00048 & 0,33815 & 198,6 & 5,0 & 201,5 & 7,9 & 212,0 & 80,0 \\
\hline MIA_641_43 & 217 & 151 & 0,7 & 0,05000 & 0,00320 & 0,21700 & 0,01400 & 0,03132 & 0,00052 & 0,26159 & 198,8 & 5,2 & 196,0 & 12,0 & 210,0 & 120,0 \\
\hline MIA_641_36 & 1.061 & 1.300 & 1,2 & 0,05000 & 0,00160 & 0,21390 & 0,00710 & 0,03139 & 0,0003 & 0,12088 & 199,3 & 4,4 & 196,5 & 5,9 & 206,0 & 67,0 \\
\hline MIA_641_25 & 586 & 537 & 0,9 & 0,05200 & 0,00220 & 0,22540 & 0,00970 & 0,03141 & 0,00033 & 0,04471 & 198,9 & 4,5 & 206,0 & 8,1 & 264,0 & 85,0 \\
\hline MIA_641_35 & 688 & 779 & 1,1 & 0,04930 & 0,00190 & 0,20890 & 0,00770 & 0,03146 & 0,00032 & 0,10291 & 199,9 & 4,5 & 191,6 & 6,5 & 158,0 & 73,0 \\
\hline MIA_641_49 & 559 & 437 & 0,8 & 0,04970 & 0,00210 & 0,21740 & 0,00840 & 0,03152 & 0,00034 & 0,10000 & 200,2 & 4,6 & 198,5 & 7,0 & 183,0 & 79,0 \\
\hline MIA_641_20 & 1.026 & 1.710 & 1,7 & 0,05250 & 0,00140 & 0,22830 & 0,00620 & 0,03154 & 0,00028 & 0,19024 & 199,6 & 4,4 & 208,1 & 5,1 & 292,0 & 57,0 \\
\hline MIA_641_12 & 475 & 407 & 0,9 & 0,05120 & 0,00210 & 0,22400 & 0,00900 & 0,03158 & 0,00035 & 0,13340 & 200,2 & 4,6 & 204,4 & 7,4 & 238,0 & 80,0 \\
\hline MIA_641_42 & 621 & 932 & 1,5 & 0,05110 & 0,00210 & 0,22150 & 0,00930 & 0,03157 & 0,00036 & 0,11950 & 200,1 & 4,6 & 202,2 & 7,7 & 246,0 & 81,0 \\
\hline MIA_641_3 & 1.430 & 3.620 & 2,5 & 0,05070 & 0,00160 & 0,22260 & 0,00790 & 0,03159 & 0,00056 & 0,43028 & 200,3 & 5,3 & 203,4 & 6,5 & 219,0 & 67,0 \\
\hline MIA_641_16 & 492 & 359 & 0,7 & 0,05040 & 0,00180 & 0,22200 & 0,00780 & 0,0316 & 0,00036 & 0,14768 & 200,5 & 4,6 & 204,1 & 6,4 & 228,0 & 69,0 \\
\hline MIA_641_19 & 1.000 & 733 & 0,7 & 0,05090 & 0,00130 & 0,22340 & 0,00630 & 0,03159 & 0,00037 & 0,35902 & 200,3 & 4,6 & 204,9 & 5,1 & 238,0 & 55,0 \\
\hline MIA_641_18 & 602 & 803 & 1,3 & 0,05930 & 0,00230 & 0,25800 & 0,01000 & 0,03205 & 0,00034 & 0,26440 & 201,1 & 4,6 & 232,0 & 7,9 & 530,0 & 79,0 \\
\hline MIA_641_31 & 819 & 1.091 & 1,3 & 0,05220 & 0,00190 & 0,22890 & 0,00890 & 0,0321 & 0,00039 & 0,29312 & 203,2 & 4,8 & 208,9 & 7,3 & 271,0 & 75,0 \\
\hline MIA_641_6 & 372 & 685 & 1,8 & 0,08320 & 0,00760 & 0,38800 & 0,04400 & 0,03217 & 0,00095 & 0,71166 & 195,8 & 7,0 & 324,0 & 30,0 & $1.190,0$ & 180,0 \\
\hline MIA_641_26 & 499 & 547 & 1,1 & 0,05300 & 0,00220 & 0,23400 & 0,01000 & 0,03221 & 0,00036 & 0,27914 & 203,7 & 4,7 & 212,9 & 8,3 & 298,0 & 83,0 \\
\hline MIA_641_33 & 990 & 788 & 0,8 & 0,04920 & 0,00180 & 0,21170 & 0,00780 & 0,03222 & 0,00038 & 0,13888 & 204,7 & 4,8 & 195,0 & 6,5 & 165,0 & 72,0 \\
\hline MIA_641_9 & 1.152 & 1.658 & 1,4 & 0,05010 & 0,00120 & 0,22420 & 0,00560 & 0,03225 & 0,00043 & 0,40189 & 204,6 & 4,9 & 204,9 & 4,6 & 197,0 & 51,0 \\
\hline MIA_641_39 & 654 & 646 & 1,0 & 0,05220 & 0,00250 & 0,22800 & 0,01100 & 0,03236 & 0,0004 & 0,40418 & 204,8 & 4,9 & 205,4 & 8,4 & 259,0 & 85,0 \\
\hline MIA_641_4 & 387 & 359 & 0,9 & 0,05050 & 0,00200 & 0,22480 & 0,00970 & 0,03238 & 0,00045 & 0,33928 & 205,4 & 5,0 & 205,6 & 7,9 & 199,0 & 77,0 \\
\hline MIA_641_27 & 486 & 464,2 & 1,0 & 0,08100 & 0,00660 & 0,37800 & 0,03900 & 0,03238 & 0,0006 & 0,80806 & 197,6 & 5,7 & 306,0 & 24,0 & $1.000,0$ & 140,0 \\
\hline MIA_641_34 & 866 & 818 & 0,9 & 0,05030 & 0,00160 & 0,22290 & 0,00690 & 0,03238 & 0,00035 & 0,13619 & 205,4 & 4,7 & 204,4 & 5,8 & 215,0 & 64,0 \\
\hline MIA_641_32 & 1.440 & 1.200 & 0,8 & 0,08010 & 0,00330 & 0,35300 & 0,01500 & 0,03243 & 0,00033 & 0,13952 & 198,1 & 4,6 & 307,0 & 12,0 & $1.136,0$ & 80,0 \\
\hline MIA_641_11 & 450 & 361 & 0,8 & 0,05140 & 0,00190 & 0,25000 & 0,01100 & 0,03415 & 0,0007 & 0,51803 & 216,2 & 6,2 & 225,6 & 8,6 & 272,0 & 74,0 \\
\hline MIA_641_10 & 726 & 1.510 & 2,1 & 0,05250 & 0,00190 & 0,25070 & 0,00960 & 0,03475 & 0,00047 & 0,38602 & 219,7 & 5,3 & 226,4 & 7,9 & 298,0 & 74,0 \\
\hline MIA_641_15 & 775 & 826 & 1,1 & 0,06090 & 0,00160 & 0,33700 & 0,01200 & 0,04037 & 0,0008 & 0,67171 & 252,1 & 6,9 & 295,4 & 9,2 & 611,0 & 58,0 \\
\hline MIA_641_48 & 186 & 96,7 & 0,5 & 0,06670 & 0,00480 & 0,58700 & 0,06900 & 0,0572 & 0,0058 & 0,90747 & 352,9 & 35,9 & 433,0 & 42,0 & 770,0 & 150,0 \\
\hline MIA_641_41 & 1.311 & 646 & 0,5 & 0,08620 & 0,00150 & 1,45200 & 0,03500 & 0,1228 & 0,0019 & 0,73492 & 727,3 & 18,3 & 909,0 & 15,0 & $1.335,0$ & 34,0 \\
\hline MIA_641_17 & 259 & 80,7 & 0,3 & 0,08020 & 0,00130 & 2,20100 & 0,04000 & 0,199 & 0,0019 & 0,38408 & $1.168,2$ & 25,6 & $1.179,0$ & 13,0 & $1.205,0$ & 34,0 \\
\hline
\end{tabular}

